\title{
Citrus tristeza virus p23: Determinants for Nucleolar Localization and Their Influence on Suppression of RNA Silencing and Pathogenesis
}

\author{
Susana Ruiz-Ruiz, ${ }^{1,2}$ Nuria Soler, ${ }^{2}$ Jesús Sánchez-Navarro, ${ }^{1}$ Carmen Fagoaga, ${ }^{2}$ Carmelo López, ${ }^{1,3}$ \\ Luis Navarro, ${ }^{2}$ Pedro Moreno, ${ }^{2}$ Leandro Peña, ${ }^{2}$ and Ricardo Flores ${ }^{1}$ \\ ${ }^{1}$ Instituto de Biología Molecular y Celular de Plantas (IBMCP), Consejo Superior de investigaciones Científicas-Universidad \\ Politécnica de Valencia, Spain; ${ }^{2}$ Instituto Valenciano de Investigaciones Agrarias (IVIA), Moncada, Valencia, Spain; and \\ ${ }^{3}$ Instituto de Conservación y Mejora de la Agrodiversidad Valenciana (COMAV), Universidad Politécnica de Valencia, Spain \\ Submitted 13 August 2012. Accepted 29 October 2012.
}

Citrus tristeza virus (CTV) encodes a singular protein (p23, 209 amino acids) with multiple functions, including RNA silencing suppression (RSS). Confocal laser-scanning microscopy of green fluorescent protein (GFP)-p23 agroexpressed in Nicotiana benthamiana revealed its accumulation in the nucleolus, Cajal bodies, and plasmodesmata. To dissect the nucleolar localization signal (NoLS) typically associated with basic motifs, seven truncated and 10 pointmutated versions of $\mathbf{p 2 3}$ were assayed. Deletion mutants showed that regions 50 to 86 and 100 to 157 (excluding fragment 106 to 114), both with basic motifs and the first with a zinc-finger, contain the (bipartite) NoLS. Alanine substitutions delimited this signal to three cysteines of the Zn-finger and some basic amino acids. RSS activity of p23 in $N$. benthamiana was abolished by essentially all mutants, indicating that it involves most $\mathbf{p 2 3}$ regions. The necroticinducing ability of p23 when launched in $N$. benthamiana from Potato virus $X$ was only retained by deletion mutant 158-209 and one substitution mutant, showing that the $\mathrm{Zn}$ finger and flanking basic motifs form part of the pathogenic determinant. Ectopic expression of p23 and some deletion mutants in transgenic Mexican lime demarcated a similar determinant, suggesting that p23 affects related pathways in citrus and $N$. benthamiana. Both RSS activity and pathogenicity of p23 appear related to its nucleolar localization.

Citrus tristeza virus (CTV)_family Closteoviridae, genus Closterovirus - is restricted in natural infections to the phloem of some species of two genera of the family Rutaceae (BarJoseph et al. 1989; Moreno et al. 2008), with the virus accumulating at significantly higher titers in Mexican lime (Citrus aurantifolia (Christm.) Swing.) and sweet orange (C. sinensis L. Osb.) than in sour orange (C. aurantium L.) (Folimonova et al. 2008; Ruiz-Ruiz et al. 2011). However, when agroinocu-

S. Ruiz-Ruiz and N. Soler contributed equally to this work.

Corresponding author: R. Flores; Telephone: 34-963877861; Fax: 34963877859; E-mail: rflores@ibmcp.upv.es

* The $\boldsymbol{e}$-Xtra logo stands for "electronic extra" and indicates three supplementary figures and one supplementary table are published online. Also, Figure 6 appears in color online.

(C) 2013 The American Phytopathological Society lated, CTV may also cause systemic infection and symptoms in the presumed non-host Nicotiana benthamiana (Ambrós et al. 2011). CTV has the largest $(19.3 \mathrm{~kb})$ genome reported for a plant monopartite single-stranded (ss)RNA (+) virus, organized in 12 open reading frames (ORF) potentially coding for at least 17 protein products flanked by $5^{\prime}$ and $3^{\prime}$ untranslated regions (UTR) (Karasev et al. 1995; Mawassi et al. 1996; Vives et al. 1999; Yang et al. 1999). Whereas the genomic (g)RNA directs translation of the two $5^{\prime}$-proximal ORF encoding components of the replicase complex, the $3^{\prime}$-proximal ORF encoding 10 proteins are expressed from 3 '-coterminal subgenomic (sg)RNAs (Hilf et al. 1995). Three of these proteins are RNA silencing suppressors (RSS) when expressed in Nicotiana spp.: p25 and p23, with an inter- and intracellular mode of action, respectively, and p20 that operates both ways ( $\mathrm{Lu}$ et al. 2004).

Viruses encode in their genomes one or more RSS to counteract the RNA-based antiviral response of their hosts mediated by the virus-derived small (vs)RNAs (Csorba et al. 2009; Ding 2010). In plants infected by ssRNA viruses, these vsRNAs result from processing by DICER-like (DCL) enzymes (Jacobson et al. 1999; Qi et al. 2005) of the snap-folded viral ssRNA itself (Molnar et al. 2005) and, particularly, of the double-stranded (ds)RNA generated by the viral RNA replicase or by host RNAdependent RNA polymerases (RDR) (Dalmay et al. 2000; Voinnet 2008). The vsRNAs then prime and lead an RNase H-like Argonaute protein (AGO) at the core of the RNAinduced silencing complex (RISC) (Hamilton and Baulcombe 1999; Vaucheret 2008) for inactivating their cognate viral ssRNAs (Omarov et al. 2007; Pantaleo et al. 2007).

Like other viral RSS, CTV-p23 (209 amino acids) is a multifunctional protein because, in addition to suppressing RNA silencing, it has been involved in regulating the asymmetrical accumulation of CTV RNA strands (Satyanarayana et al. 2002) and in eliciting CTV-like symptoms when expressed ectopically as a transgene in several Citrus spp. (but not in Nicotiana spp.) (Fagoaga et al. 2005; Ghorbel et al. 2001), with recent data supporting the idea that, most likely, it is also the CTV determinant of the seedling yellows syndrome in sour orange and grapefruit (C. paradisi Macf.) (Albiach-Martí et al. 2010). Moreover, the ectopic expression of p23 enhances systemic infection (and virus accumulation) in sour orange and enables CTV to escape from the phloem of sweet and sour orange, suggesting that constraints to CTV movement in citrus, particularly in sour orange, may result, at least in part, from RNA silencing or from p23 involvement in virus movement (Fagoaga 
et al. 2011). From a biochemical viewpoint, p23 is an RNAbinding protein with a putative zinc-finger domain and some basic motifs (López et al. 2000); and, from an evolutionary perspective, p23 is unique to CTV, with no homologues found in other closteroviruses, including the type species of the genus Beet yellows virus (BYV), despite CTV and BYV sharing multiple homologous genes (Dolja et al. 2006). Therefore, p23 might have evolved for specific interactions of CTV with its citrus hosts.

Here, we report that p23 accumulates preferentially in the nucleolus, being the first closterovirus protein with such a subcellular localization, as well as in plasmodesmata. By deleting and substituting specific regions and amino acids of p23 we have i) mapped its bipartite nucleolar localization signal (NoLS) and ii) determined the effects of these deletions and substitutions in suppressing RNA silencing in $N$. benthamiana and in eliciting a pathogenic reaction, when expressed as a sRNA of Potato virus $X$ (PVX) in this species and as a transgene in a sensitive citrus host.

\section{RESULTS}

\section{CTV-p23 accumulates preferentially}

in the nucleolus and Cajal bodies and in plasmodesmata.

The presence of p23 in CTV, with no homologue in other closteroviruses, made it particularly interesting to determine its major subcellular accumulation sites. For this purpose, the $3^{\prime}$ terminus of gene $p 23$ from CTV isolate T36 was fused to the $5^{\prime}$ terminus of the green fluorescent protein (GFP) gene and this construct, under the control of the $35 \mathrm{~S}$ promoter from Cauliflower mosaic virus (CaMV) and the nopaline synthase terminator (NOS-t), was agroinfiltrated in leaves of $N$. benthamiana. Leaf examination by confocal laser-scanning microscopy at 2 days post agroinfiltration (dpai) revealed the preferential accumulation of the p23-GFP fusion protein in the nucleus and, more specifically, in the nucleolus and nucleolar bodies resembling Cajal bodies, while free GFP was found in the nucleus and cytoplasm (but not in the nucleolus) in the agroinfiltrated control (Fig. 1). To further confirm these observations, the construct expressing the fusion protein $\mathrm{p} 23-\mathrm{GFP}$ was co-agroinfiltrated with another construct in the same vector expressing fibrillarin fused to the red fluorescent protein (RFP), which specifically marks the nucleolus and Cajal bodies (Barneche et al. 2000; Kim et al. 2007). Overlay of both images revealed a perfect match (Fig. 2), thus substantiating the accumulation of p23 in these subnuclear compartments. This perfect match and the lack of any apparent cellular aber- ration made unlikely an artefactual localization for $\mathrm{p} 23-\mathrm{GFP}$, a point further confirmed by mutational analyses and by the use of an alternative expression vector (discussed below). Moreover, co-agroinfiltration of $\mathrm{p} 23-\mathrm{GFP}$ and fibrillarin-RFP in young leaves of $C$. macrophylla also showed the preferential accumulation of p23 in the nucleolus of this sensitive natural host of CTV (Supplementary Fig. S1).

On the other hand, p23 was also detected in agroinfiltrated leaves in punctuated structures at the cell wall that could represent plasmodesmata (Fig. 1). To corroborate this localization, the construct expressing p23-GFP was co-agroinfiltrated with a second construct in the same vector expressing the movement protein of Tobacco mosaic virus (TMV-MP) fused to the RFP, which should mark plasmodesmata specifically (Tomenius et al. 1987). However, overlay of both images showed p23GFP in the nucleolus as well as in peripheral nuclear aggregates of both fusion proteins, suggesting an interaction between them, with TMV-MP-RFP being dragged by p23-GFP to its predominant subcellular localization site (data not shown). To circumvent this problem, we co-agroinfiltrated two constructs expressing p23-RFP and the movement protein of Prunus necrotic ringspot virus (PNRSV-MP) fused to the yellow fluorescent protein (YFP), a marker of plasmodesmata (Herranz et al. 2005). Overlay of the resulting images supports localization of p23 also in plasmodesmata (Fig. 2).

Altogether, these results strongly suggested the existence in p23 of a nuclear localization signal (NLS) and, more specifically, an NoLS, as well as of a plasmodesmatal localization signal (PLS). Because the motifs characteristically forming part of NLS and NoLS are relatively well known, we next examined their presence in $\mathrm{p} 23$.

\section{Dissection of the p23 determinants of nucleolar localization.}

NLS and NoLS are formed by short motifs rich in basic amino acids that mediate the nuclear or nucleolar import of proteins, wherein they are contained, by binding to receptors known as importins (Hiscox 2007; Kosugi et al. 2009; Ryabov et al. 2004). Inspection of the amino acid sequence of p23 revealed three arginine- and lysine-rich regions or motifs (positions 51 to 86, 106 to 114 , and 143 to 155) (Fig. 3), the first including the putative Zn-finger domain (López et al. 2000). To examine whether one or more of these regions or motifs were part of the p23 NoLS, we constructed seven p23 mutants: p23 $\Delta 50-86$, p23 $\Delta 50-66$, and p23 $\Delta 67-86$ (deleting the first region or portions thereof); p23 $\Delta 106-114$ (deleting the second motif); p23 $\Delta 100-209$ (deleting the second and third motifs);
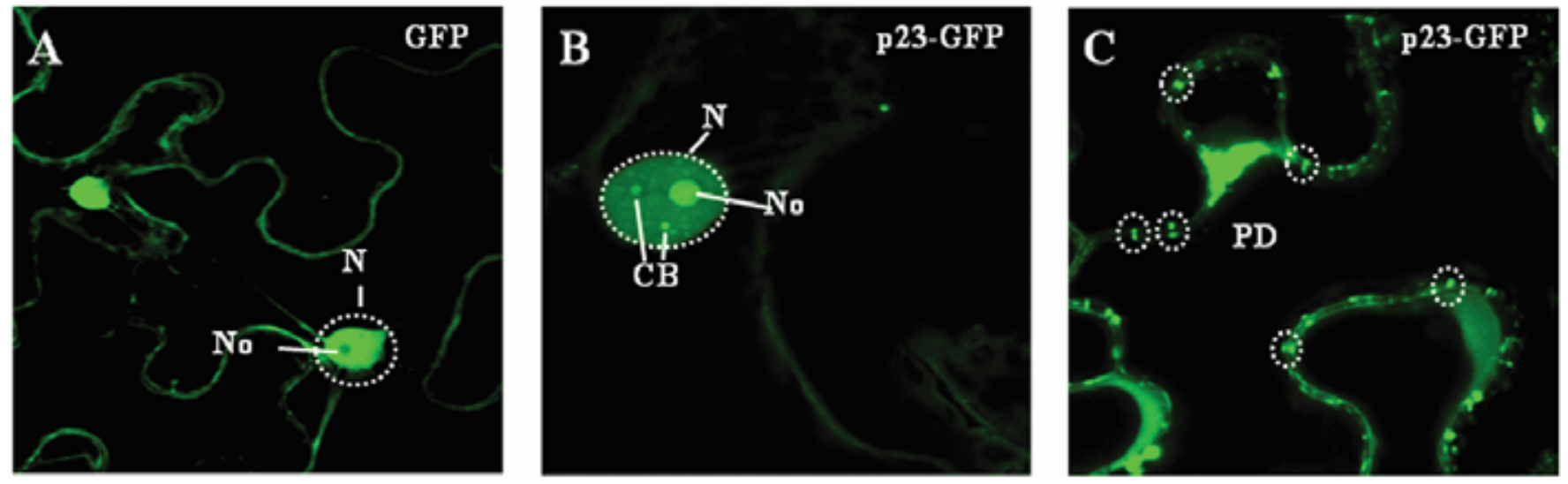

Fig. 1. Confocal laser-scanning microscopy of Nicotiana benthamiana leaves agroinfiltrated with constructs expressing A, the green fluorescent protein (GFP) itself or $\mathbf{B}$ and $\mathbf{C}$, fused to the C-terminus of the Citrus tristeza virus (CTV)-p23. Free GFP accumulates in the nucleus (N) and cytoplasm, being largely excluded from the nucleolus (No), while the fusion protein p23-GFP accumulates in the nucleolus, Cajal bodies (CB), and plasmodesmata (PD). Examinations were performed 2 days post agroinfiltration. 
p23 $\Delta 125-209$ (only deleting the third motif); and p23 $\Delta 158$ 209 (deleting the C-terminal 51 amino acids without affecting any of the three regions or motifs). The $3^{\prime}$ termini of these mutated versions of $p 23$ were fused to the $5^{\prime}$ terminus of the GFP gene and the resulting constructs were individually agroinfiltrated in $N$. benthamiana with the construct expressing fibrillarin-RFP.

Only p23 $\Delta 106-114$ and p23 $2158-209$ localized to the nucleolus and Cajal bodies like the full-length p23, whereas the remaining mutants were found in the nucleus but not in the nucleolus of transfected epidermal cells (Fig. 4). Therefore, neither the second basic motif (positions 106 to 114) nor the last
C-terminal 51 amino acids (positions 158 to 209) contribute to the NoLS. On the other hand, the region encompassing positions 50 to 86 , as well as its segments delimited by positions 50 to 66 and 67 to 86, are critical for nucleolar targeting, as also is the region delimited by positions 125 to 157 (because p23 $\Delta 158-209$ but not p23 $\Delta 125-209$ is targeted to the nucleolus). Altogether, these results strongly support a bipartite NoLS (encompassing positions 50 to 86 and 125 to 157). To better map the NoLS existing within positions 125 to 157 , we constructed a new deletion mutant, p23 $\Delta 143-209$ (including the third motif rich in basic amino acids delimited by positions 143 to 155 ) which, in contrast with mutant p23 $\Delta 158-209$, did
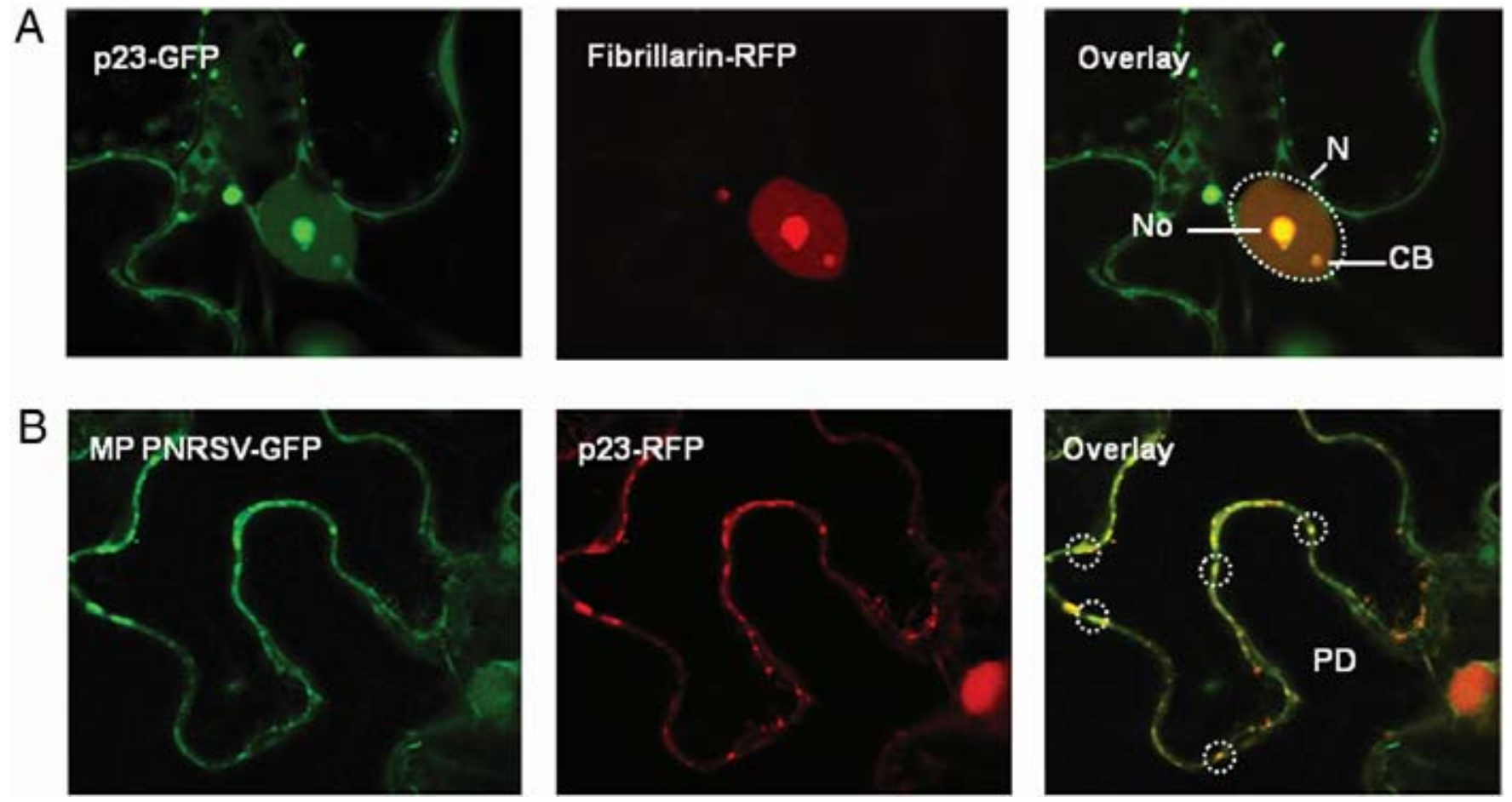

Fig. 2. Confocal laser-scanning microscopy of Nicotiana benthamiana leaves co-agroinfiltrated with constructs expressing the A, protein fusions p23-green fluorescent protein (GFP) and fibrillarin-red fluorescent protein (RFP) and B, the protein fusions p23-RFP and the movement protein of Prunus necrotic ringspot virus fused to the yellow fluorescent protein (PNRSV-MP-YFP). Overlay of the corresponding images confirms the predominant accumulation of p23-GFP in the nucleolus (No) and Cajal bodies (CB), and in plasmodesmata (PD). Fluorescence was observed 2 days post agroinfiltration.

\section{A MDNTSGQTFVSVNLSDESNTATTDVEPVSSEADRLDFLQKMNPIIIDALI RKNSY QGARFRARIIGVCVDCGRK HDK GLK TER K CK VNNTQSQNEVAHMLMHDPV ${ }_{155}^{106} \mathrm{Y}$ LNKRKARAFSNAEIFAIDLVMYTKERQLAIDLAAE REK TRLARRHPMRSPEETPE YYKFGRTAKAMLPDINAVDVGDNEETSSEYPVSLSVSGGVLREHHFI}

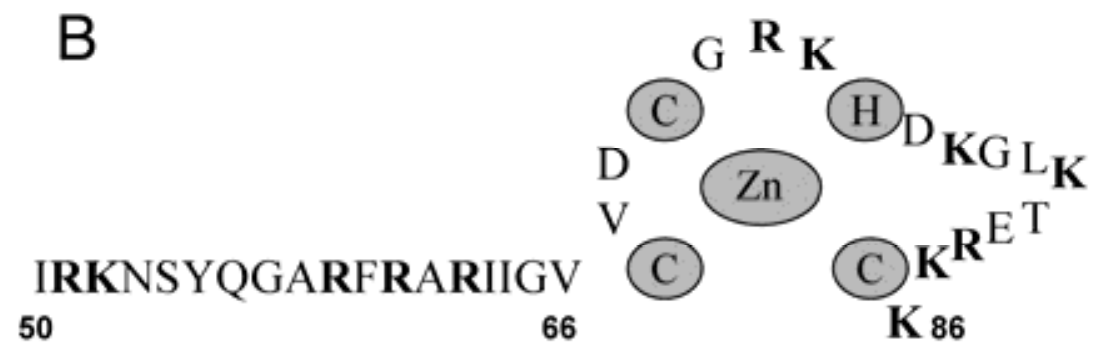

Fig 3. A, Amino acid sequence of p23 from Citrus tristeza virus (isolate T36) with the three arginine- and lysine-rich regions or motifs delimited by positions 51 to 86,106 to 114 , and 143 to 155 highlighted with different colors and $\mathbf{B}$, the putative zinc-finger domain with the coordinating histidine and cysteines. 
not localize in the nucleolus (data not shown). Hence, amino acids 143 to 155 are also required for nucleolar import of p23. Incidentally, although a detailed analysis including co-agroinfiltration of the seven p23 mutants with the PNRSV-MP-GFP marker was not performed, we only observed plasmodesmata localization for p23 $\Delta 158-209$ and not for the remaining mutants (data not shown).

\section{Fine dissection of the bipartite NoLS of CTV-p23.}

To exclude the possibility that deleting large fragments of p23 could influence its global molecular structure and, indirectly, its subcellular localization, we additionally constructed 10 alaninesubstitution mutants of p23: p23R51/K52 and p23R59/R61/ R63 (basic amino acids preceding the Zn-finger domain); p23C68/C71/H75/C85, p23C71, and p23H75 (the four or just two individual amino acids potentially coordinating the $\mathrm{Zn}$ ion); p23R73/K74 and p23K77/K80/R83/K84/K86 (basic amino acids within the Zn-finger domain); and p23R143/K145/R147, p23R150/R151/R155, and p23R143/K145/R147/R150/R151/ R155 (basic amino acids of the second motif required for nucleolar import of p23). The $3^{\prime}$ termini of these point-mutated versions of $p 23$ were fused to the $5^{\prime}$ terminus of the GFP gene and the resulting constructs were individually agroinfiltrated in $N$. benthamiana with the construct expressing fibrillarin-RFP.

The seven mutants with substitutions mapping within the region delimited by positions 50 to 86 (the $\mathrm{Zn}$-finger domain and preceding basic amino acids) lost their nucleolar localization, except $\mathrm{p} 23 \mathrm{H} 75$, that behaved essentially like the wild-type (wt) p23 (Fig. 5). Intriguingly, the quadruple mutant affecting the three cysteines and the histidine potentially binding the $\mathrm{Zn}$ ion (positions 68,71, 75, and 85) induced a redistribution of the fibrillarin which, in addition to the nucleolus and Cajal bodies, was also observed in other subnuclear bodies of a size similar or even higher than the nucleolus. The mutant p23 accumulated in the subnuclear bodies, which should not be genuine but, most likely, resulted from this protein attracting some fibrillarin, and also in others not labeled by fibrillarin as revealed by the overlay (Fig. 5).

The remaining three mutants with substitutions affecting the region delimited by positions 143 to 155 (the second motif forming part of the p23 NoLS) also lost their nucleolar localization. However, two of them behaved like the quadruple mutant affecting the three cysteines and the histidine potentially binding the $\mathrm{Zn}$ ion (discussed above), and induced a redistribution of the fibrillarin into one or several subnuclear bodies (again, most likely not genuine) wherein the p23 mutants accumulated (Fig. 5). Collectively, the data obtained with the substitution mutants confirmed and refined the conclusion inferred with the deletion mutants: the NoLS of p23 is bipartite and has two different components, short basic motifs and a $\mathrm{Zn}$-finger domain.

\section{CTV-p23 has strict requirements}

to act as an RNA silencing suppressor.

As indicated above, p23 has RSS activity when co-expressed by agroinfiltration with GFP in the transgenic line of $N$. benthamiana 16c constitutively expressing GFP (Lu et al. 2004). To further validate this result and to determine whether specific regions or motifs of p23 are necessary for suppressing RNA silencing, the wt form and its seven deletion mutants used previously in the subcellular localization experiments were individually co-agroinfiltrated with a plasmid expressing GFP (35SGFP) into leaves of the same transgenic line 16c (Brigneti et al. 1998). Controls for this experiments included leaves of the transgenic line co-agroinfiltrated with plasmid 35S-GFP and either the empty plasmid or plasmid 35S-HcPro expressing the RSS of Tobacco etch virus (Kasschau and Carrington 1998).
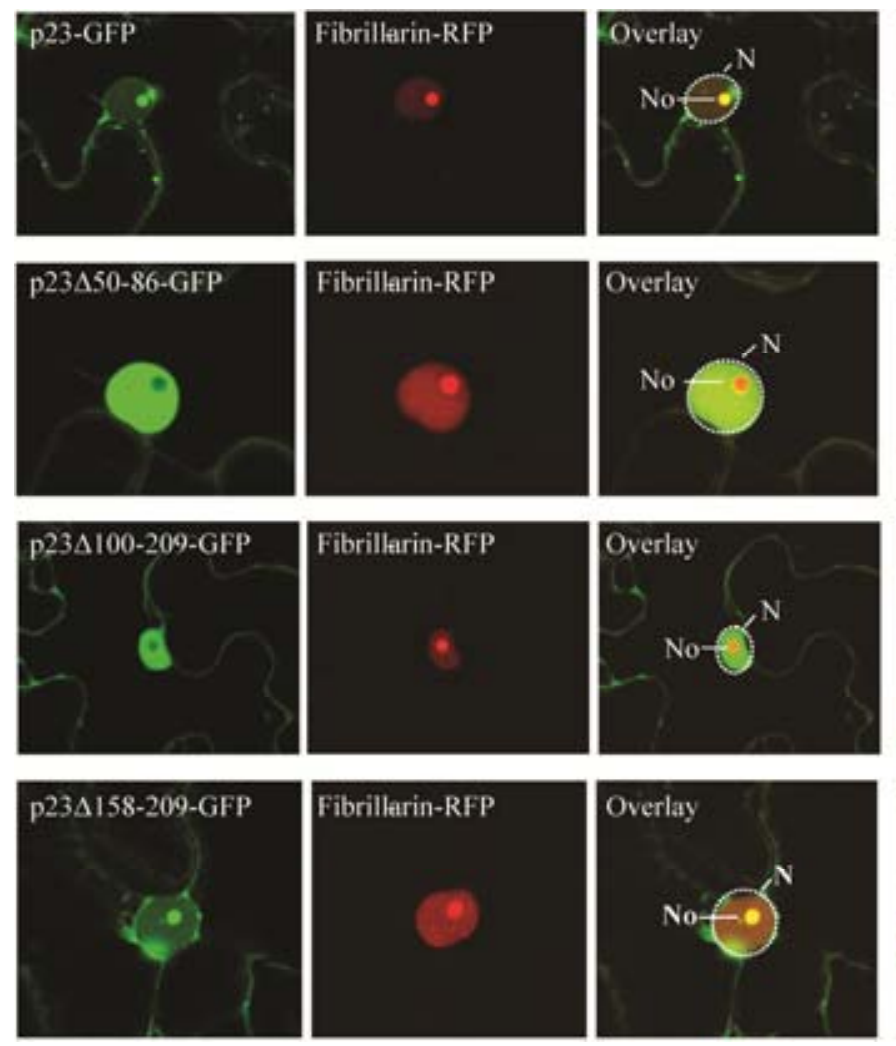
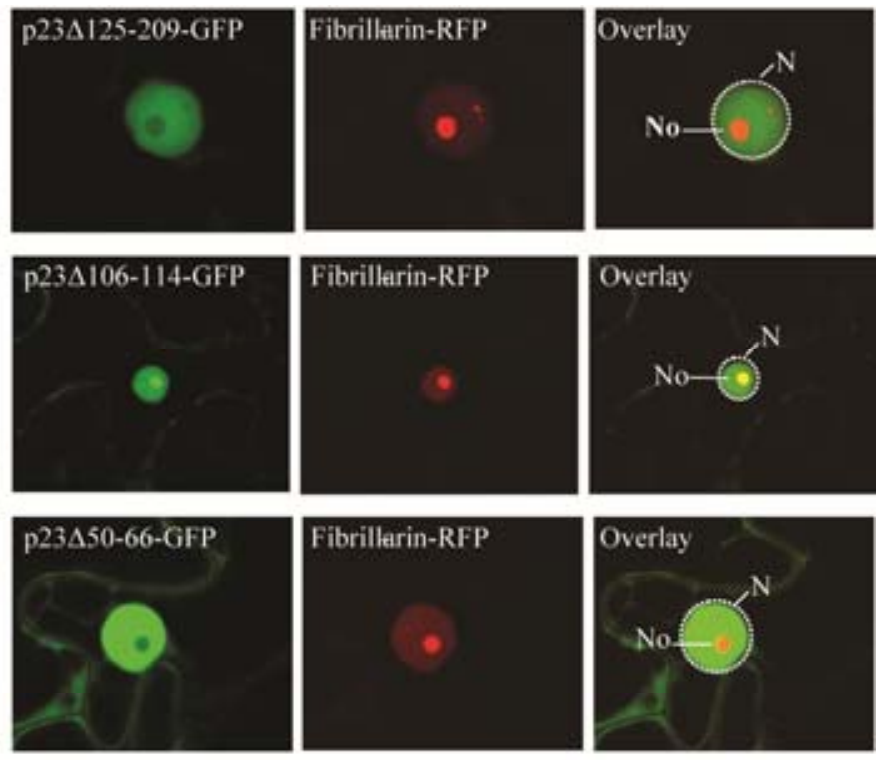
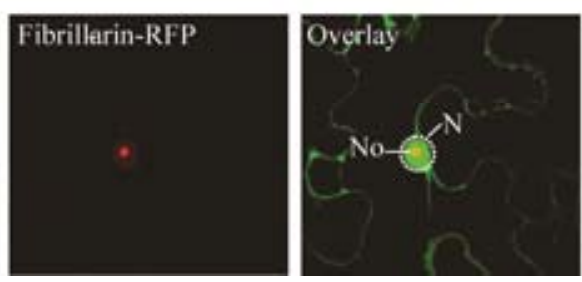

Fig 4. Confocal laser-scanning microscopy of Nicotiana benthamiana leaves, in which constructs expressing the protein fusion p23-green fluorescent protein (GFP) (and seven deletion mutants of p23 also fused to GFP) were individually co-agroinfiltrated with a construct expressing fibrillarin-red fluorescent protein (RFP). Overlays show that the nucleolar localization signal of p23 is bipartite and includes regions or motifs delimited by positions 50 to 86 and 143 to 155 . GFP fluorescence was observed 2 days post agroinfiltration. 
At 2 to 3 dpai, GFP fluorescence was observed in leaves infiltrated with plasmid 35S-GFP alone or co-infiltrated with any of the other constructs. However, whereas leaves co-infiltrated with plasmids 35S-GFP and 35S-p23 or 35S-HcPro still emitted a strong fluorescence at 6 to $7 \mathrm{dpai}$, the fluorescence declined significantly with time in leaves infiltrated with plasmid 35S-GFP alone or co-infiltrated with the empty plasmid or with any of the seven plasmids expressing the individual p23 deletion mutants, becoming almost undetectable at 6 to 7 dpai (Fig. 6). In line with these results, Northern blot hybridizations with a GFP-specific riboprobe of RNAs extracted at 6 dpai showed a clear increase of GFP-mRNA accumulation in leaves co-agroinfiltrated with plasmids 35S-GFP and either 35S-p23 or 35S-HcPro, with respect to leaves agroinfiltrated with just plasmid 35S-GFP or co-agroinfiltrated with plasmids $35 \mathrm{~S}$-GFP and the empty plasmid or any of the seven p23 deletion mutants, all of which dis- played a low GFP-mRNA accumulation similar to that resulting from the stably integrated GFP transgene. Concomitantly, strong bands with the mobility expected for GFP-specific small interfering RNAs (siRNAs) of 24, 22, and 21 nucleotides (nt) were detected in leaves expressing low GFP-mRNA levels whereas, in leaves expressing high GFP-mRNA levels, the intensity of the GFP-siRNA bands became very much attenuated (those of 24 and $22 \mathrm{nt}$ ) or undetectable (that of $21 \mathrm{nt}$ ) (Fig. 6). Both RSS (p23 and HcPro) displayed very similar effects on the inversely correlated levels of GFP-mRNA and GFP-siRNAs (Fig. 6). Leaving apart minor discrepancies regarding the optimal time for observing the RSS activity of p23, which may result from differences in the expression vector or growing conditions, our data essentially agree with those reported previously (Lu et al. 2004).

Regarding the effect on parallel co-agroinoculation experiments of the 10 substitution mutants of p23, all except $\mathrm{p} 23 \mathrm{H} 75$
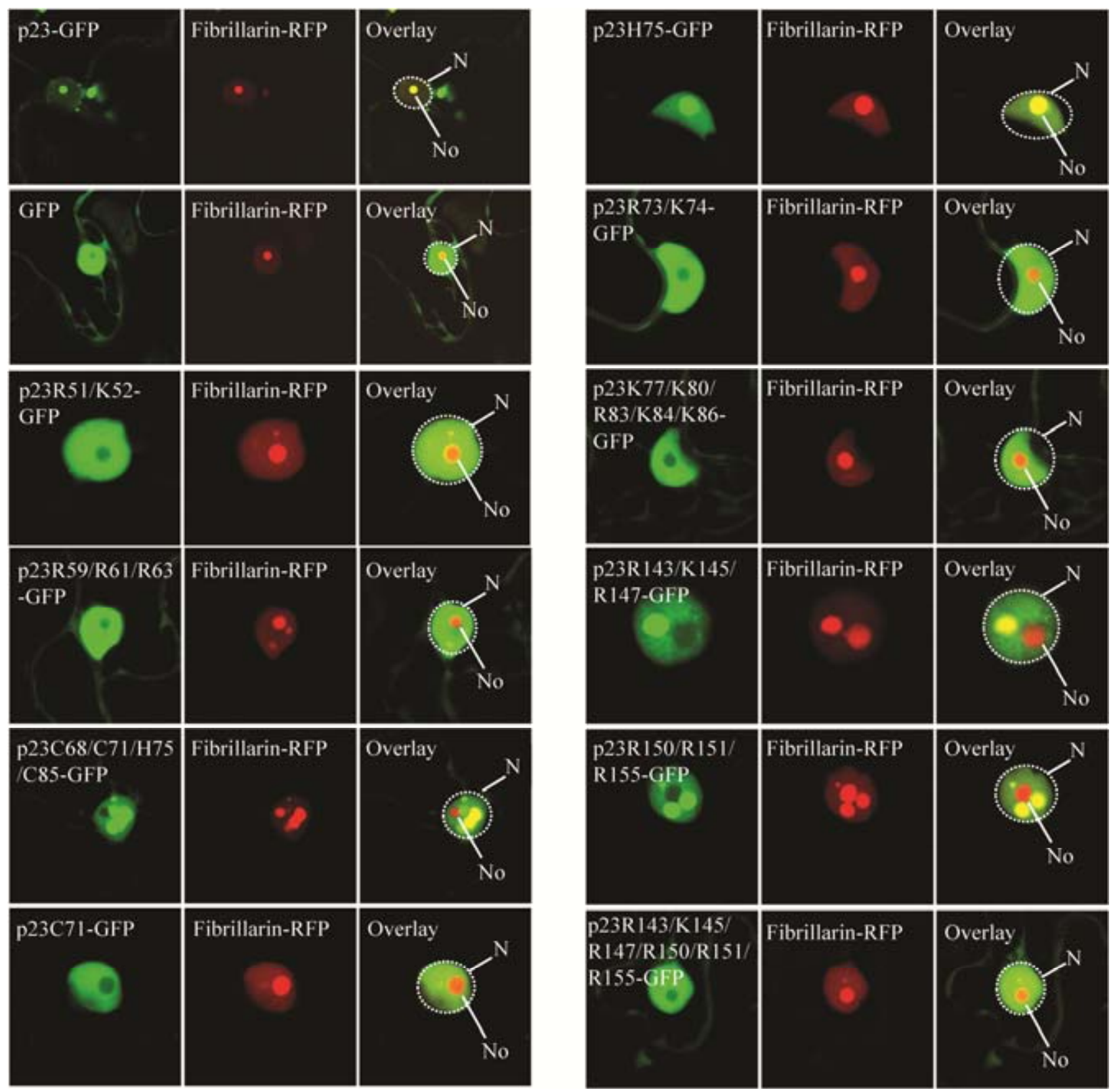

Fig 5. Confocal laser-scanning microscopy of Nicotiana benthamiana leaves in which constructs expressing the protein fusion p23-green fluorescent protein (GFP) (and 10 alanine-substitution mutants of p23 also fused to GFP) were individually co-agroinfiltrated with a construct expressing fibrillarin-red fluorescent protein (RFP). Overlays confirm that the nucleolar localization signal of p23 is bipartite and has two different components: short basic motifs and a zinc-finger domain. GFP fluorescence was observed 2 days post agroinfiltration. 
behaved as the deletion mutants: the fluorescence became almost undetectable at 6 to 7 dpai. As anticipated from these results, all substitution mutants induced low GFP-mRNA and high GFP-siRNAs, with the exception of p23H75, in which the reverse situation was observed (data not shown).

Altogether, these results showed that the RSS activity of p23 was abolished by all deletions mutants as well as by all substitution mutants except p23H75. Therefore, the RSS activity of p23 involves most regions of this protein.

\section{CTV-p23 is a pathogenic determinant in $N$. benthamiana} when expressed from the heterologous vector PVX.

In contrast to transgenic plants of different citrus species in which ectopic expression of p23 (wt) is accompanied by leaf symptoms sometimes resembling those incited by CTV in nontransgenic plants, ectopic expression of p23 in the CTV non-natural host $N$. benthamiana and in $N$. tabacum occurs without phenotypic aberrations (Fagoaga et al. 2005; Ghorbel et al. 2001), despite i) CTV T36 inducing symptoms in leaves of $N$. benthamiana (Ambrós et al. 2011), ii) p23 acting as an RSS suppressor in these two species (Lu et al. 2004), and iii) p23 accumulating at similar levels in citrus and Nicotiana spp. (Fagoaga et al. 2005). To investigate whether p23 could induce symptoms in $N$. benthamiana in a different context, this protein was expressed as a sgRNA of PVX (Voinnet et al. 1999). Although leaves mechanically inoculated with the wt PVX or its recombinant version (PVX-p23) did not exhibit visible alterations, the upper noninoculated leaves displayed vein clearing and a mild chlorotic mosaic at 7 days postinoculation (dpi) with either of the two infectious sources. However, at $10 \mathrm{dpi}$, PVX-p23 caused stunting and necrotic mottling in systemically infected leaves and stems and, at $15 \mathrm{dpi}$, the death of the plants, with no symptom accentuation being observed in PVXinfected plants (Fig. 7). Therefore, p23, like other RSS (Pruss et al. 1997; Voinnet et al. 1999), is a pathogenic determinant in $N$. benthamiana when launched from PVX. Moreover, when launched from PVX, p23-GFP also accumulated preferentially in the nucleolus of bundle sheath cells (and in the phloem but not in the xylem) (Fig. 7A) - thus confirming its subcellular localization with an alternative expression vector-and induced symptoms in $N$. benthamiana similar to those caused by the expression of p23 (data not shown).

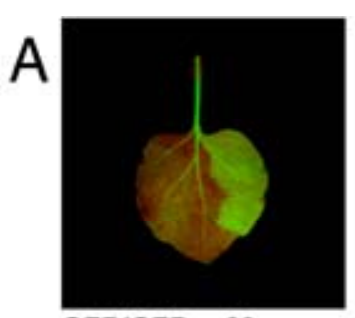

GFPIGFP+p23

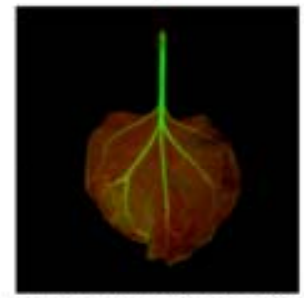

GFPIGFP+p23 $\Delta 125-209$ GFP/GFP+p23 $\Delta 106-114$

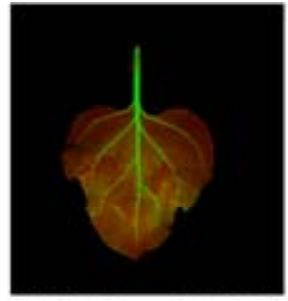

GFP/GFP+p23 $250-86$

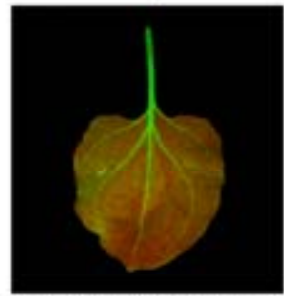

GFP/GFP+p23 $\Delta 50-66$

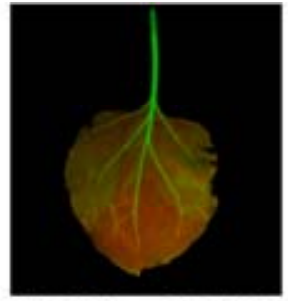

GFPIGFP+p23 $100-209$ GFP/GFP+p23 $158-209$

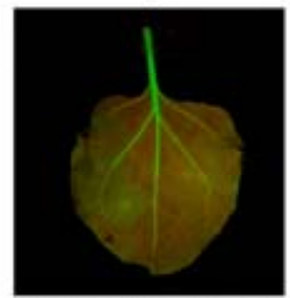

GFP/GFP+p23 $\Delta 67-86$

\section{B}

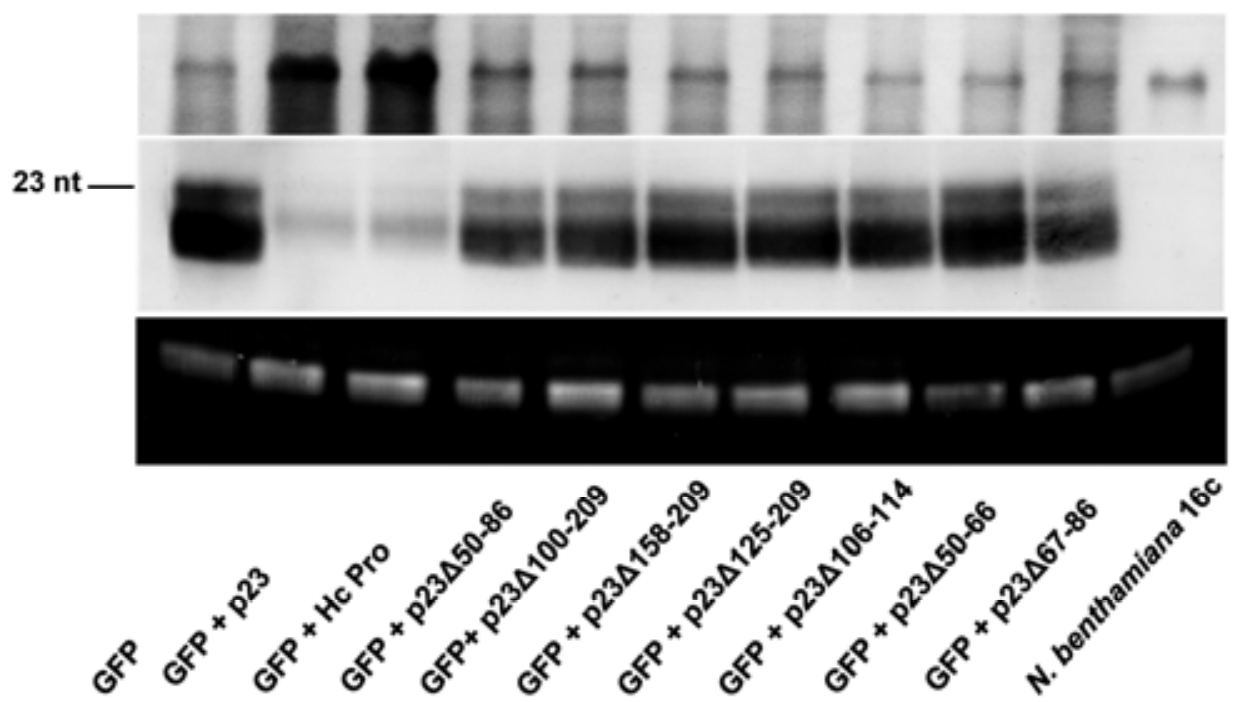

GFP mRNA

GFP siRNA

4S RNA

Fig 6. A, Confocal laser-scanning microscopy of Nicotiana benthamiana 16c leaves that were co-agroinfiltrated with the empty vector and a construct for expressing green fluorescent protein (GFP) (left half-leaf), or with constructs for expressing GFP and p23, Hc-Pro, or seven deletion mutants of p23 (right half-leaf). GFP fluorescence was observed 6 days post agroinfiltration. B, Accumulation of GFP mRNA and GFP-small interfering RNAs (siRNAs) as revealed by Northern blot hybridization with a specific riboprobe following electrophoresis in denaturing agarose $(0.8 \%)$ and polyacrylamide (17\%) gels, respectively. The $4 \mathrm{~S}$ RNAs stained with ethidium bromide are shown as a loading control. 


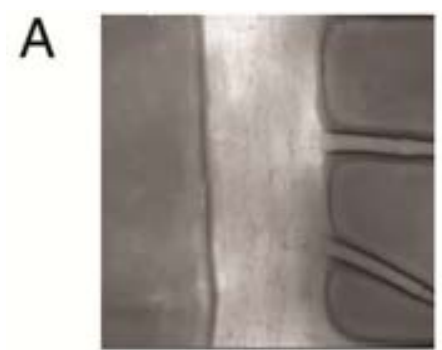

Visible

B

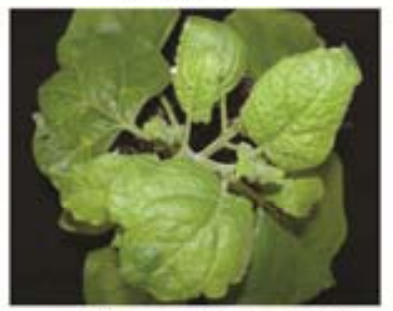

PVX + p23 (7 dpi)

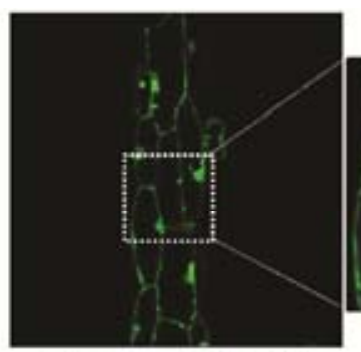

PVX + p23-GFP

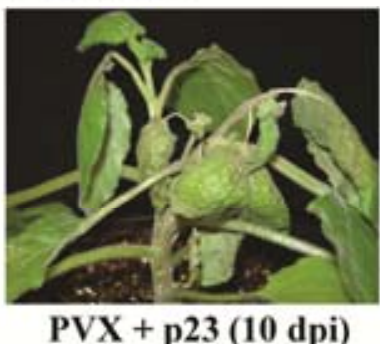

PVX + p23 (10 dpi)

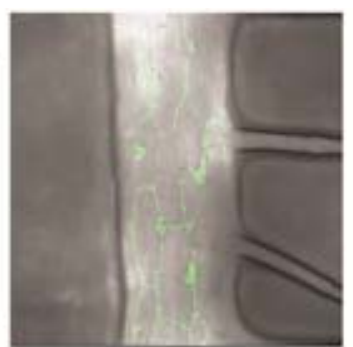

Overlay

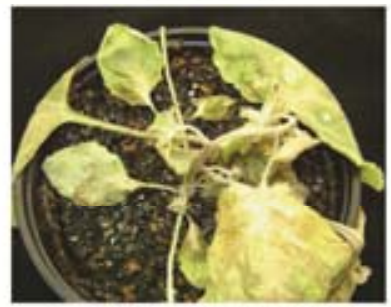

PVX + p23 (15 dpi)

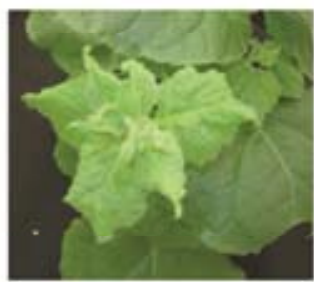

PVX

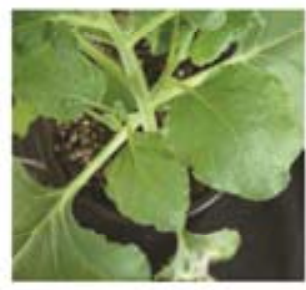

$P V X+p 23 \Delta 50-86$

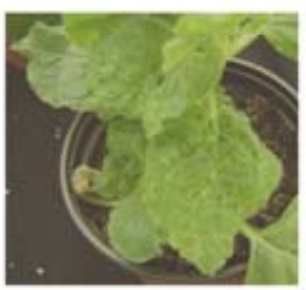

PVX + p23 $\Delta 100-209$

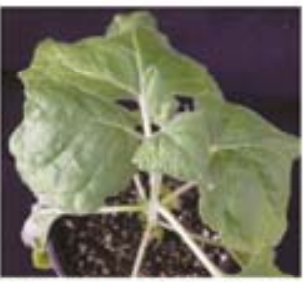

$P V X+p 23 \Delta 50-66$

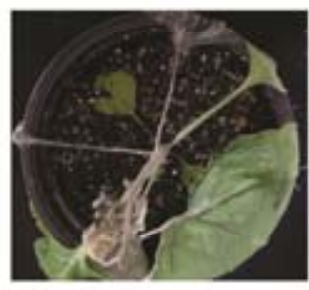

PVX + p23 2158-209

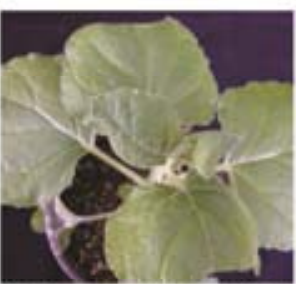

$P V X+p 23 \Delta 67-86$

$15 \mathrm{dpi}$

$15 \mathrm{dpi}$

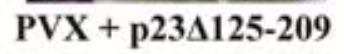

PVX + p23 $1106-114$
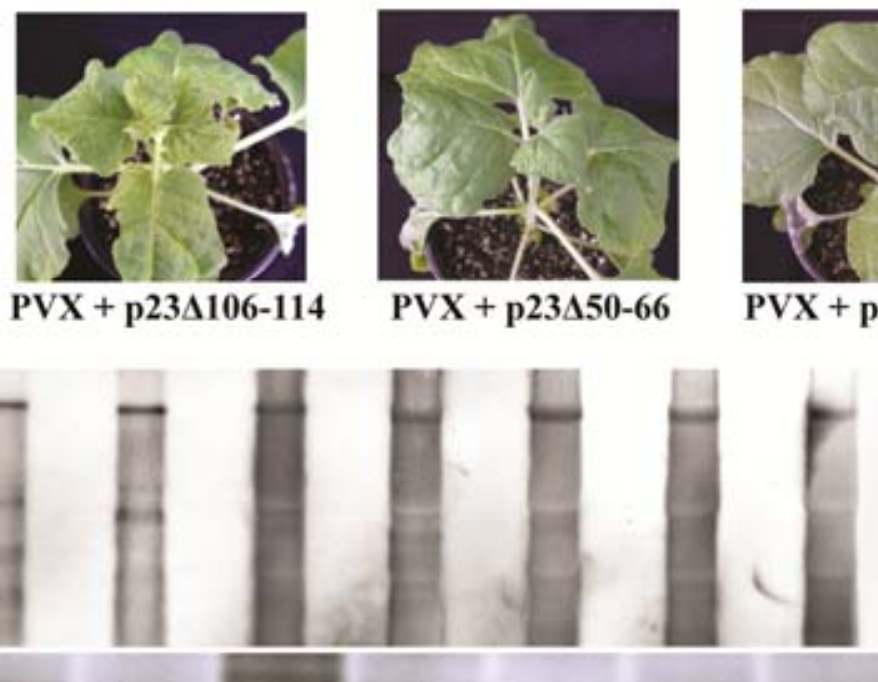

gRNA

C
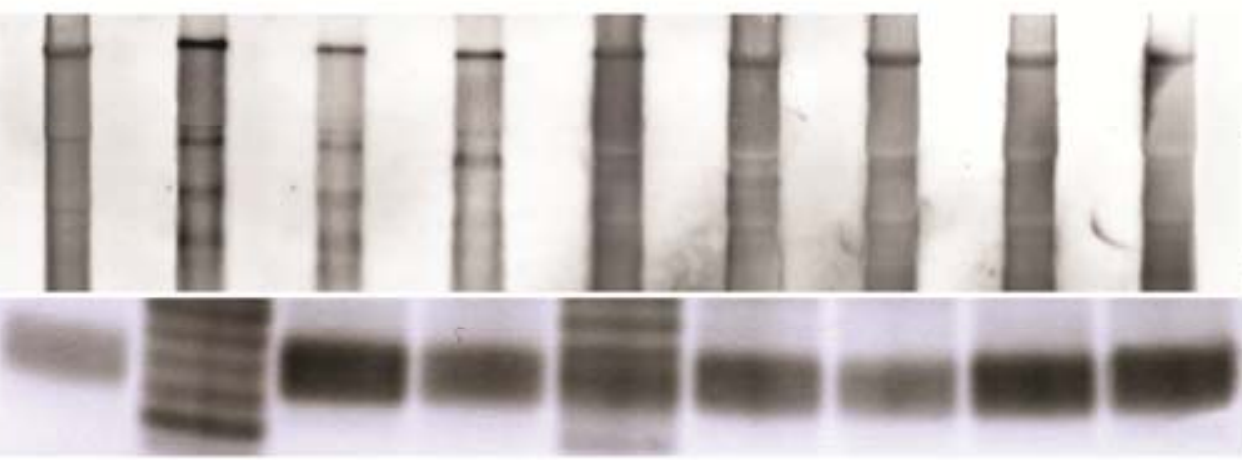

siRNA

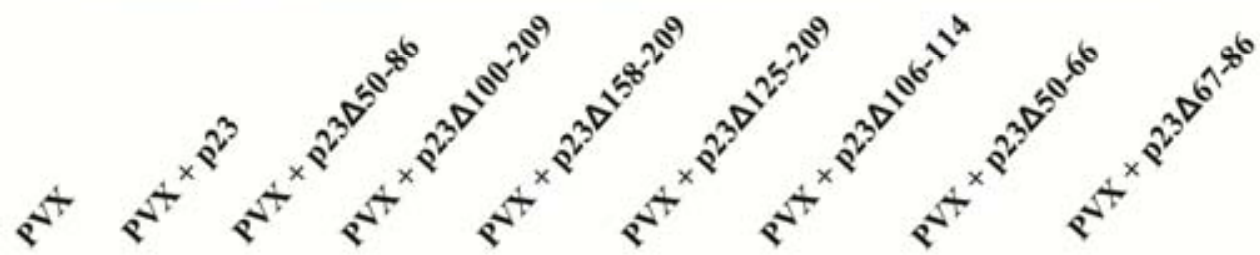

Fig 7. A, Confocal laser-scanning microscopy of vascular tissue from Nicotiana benthamiana infected by Potato virus $X$ (PVX) expressing p23-green fluorescent protein (GFP) as a viral subgenomic (sg)RNA. B, Symptoms observed in upper noninoculated leaves of N. benthamiana in which p23 (first row) and seven deletion mutants thereof (second and third rows) were individually expressed as PVX sgRNAs. C, Accumulation of PVX genomic (g)RNA and sgRNAs, and of PVX-small interfering (si)RNAs, as revealed by Northern blot hybridization with a specific riboprobe for the PVX coat protein gene following electrophoresis in denaturing agarose $(0.8 \%)$ and polyacrylamide (17\%) gels, respectively. 
To know whether the severe symptoms incited by p23 might result from suppression of virus-induced gene silencing, we examined the effects of the seven deletion and 10 substitution mutants of p23 when expressed from the corresponding PVX sgRNAs: only the p23 $\Delta 158-209$ deletion and the p23H75 substitution mutants incited symptoms (severe necrosis resulting in plant death) similar to those of the wt p23 (Fig. 7 and Supplementary Fig. S2, respectively). These results show that i) the pathogenic determinant of p23 resides in the first N-terminal 157 amino acids, and that the putative Zn-finger domain and flanking basic motifs form part of this determinant; and ii) the RSS activity and the ability to induce phenotypic aberrations are independent functions in p23 because p23 $158-209$ without the first activity retains the second ability.

To further examine the role that the interaction between PVX and p23 might have in exacerbating symptoms, we performed Northern blot analyses of RNA preparations from plants inoculated with PVX, as well as with PVX expressing p23 (wt) and its seven deletion mutants at $10 \mathrm{dpi}$. Using a riboprobe derived from the coat protein gene, no major differences were observed in the accumulation patterns of the g- and sgRNAs between the wild PVX and the different recombinants, indicating that symptom severity is not correlated with increased virus titer. However, although this riboprobe detected PVXspecific small RNAs of approximately 21 and $22 \mathrm{nt}$ in plants infected by PVX and by PVX expressing six of the seven p23 deletion mutants, these two prominent bands were replaced by several bands in the range of 18 to $25 \mathrm{nt}$ in plants infected by PVX expressing p23 (wt) and, to a lesser extent, its deletion mutant p23 $\Delta 158-209$ (Fig. 7). Because these two constructs were the only inciting necrotic symptoms, it is possible that the observed pattern could result from increased exonuclease activity in damaged tissues trimming the protruding $3^{\prime}$ termini of the vsRNAs. Consistent with these observations, a similar
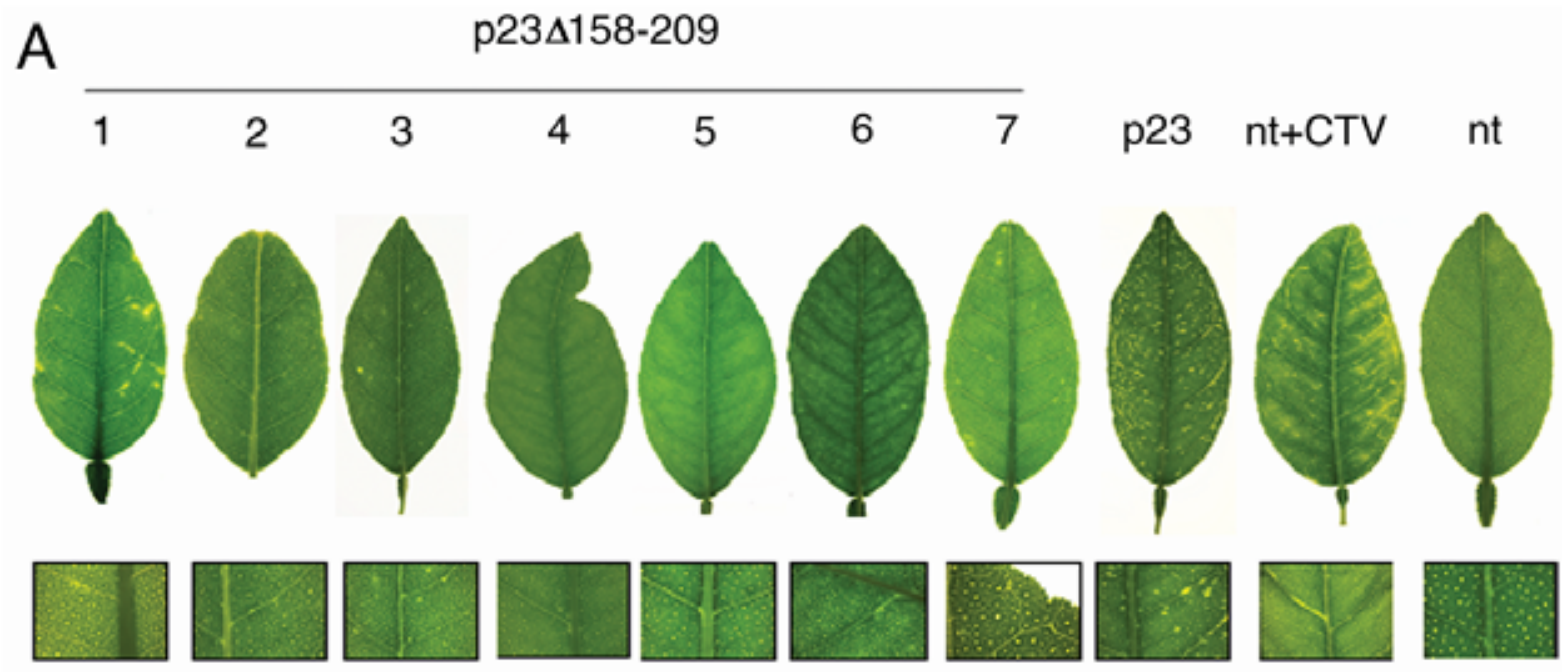
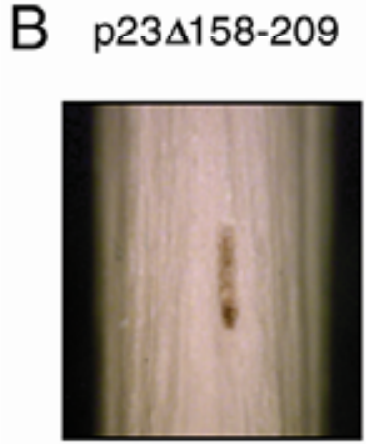

C

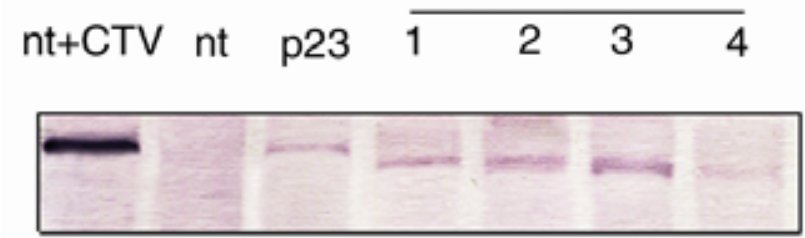

p23

p23 $\Delta 158-209$

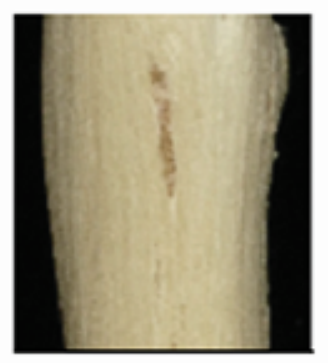

$n++C T V$

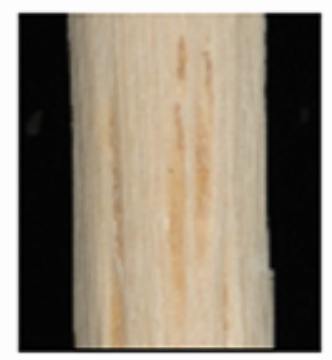

$n t+C T V n t$ nt

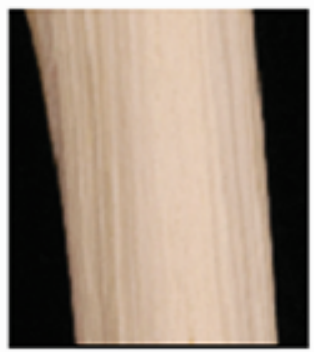

p23 $\Delta 158-209$

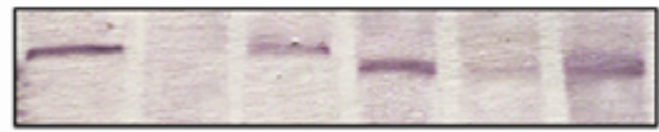

Fig. 8. A, Citrus tristeza virus (CTV)-like foliar symptoms expressed by seven transgenic lines of Mexican lime transformed with the p23 $158-209$ deletion mutant and subsequently grafted on a vigorous rootstock. Controls include a noninoculated p23-expressing transgenic plant (p23), a nontransgenic plant inoculated with a severe CTV isolate ( $\mathrm{nt}+\mathrm{CTV}$ ), and a noninoculated nontransgenic plant (nt). To better illustrate the phenotypic alteration (vein clearing), a magnification is shown below each leaf. B, Stem pitting expressed by one representative transgenic line of Mexican lime transformed with the p23 $\Delta 158-209$ deletion mutant. Controls are the same as in the previous panel. C, Accumulation of p23 and its deletion p23 $\Delta 158-209$ mutant as revealed by Western blot analysis with a specific antibody following electrophoresis in sodium dodecyl sulfate polyacrylamide (12\%) gels. 
pattern of vsRNAs was observed with p23H75, the only substitution mutant inducing necrosis similar to p23 (wt).

\section{Ectopic expression in Mexican lime of CTV-p23 and some deletion mutants delimits \\ a similar pathogenic determinant in the natural host.}

Given that p23 induces developmental aberrations resembling CTV symptoms when expressed ectopically in several citrus species. including Mexican lime (Fagoaga et al. 2005; Ghorbel et al. 2001), we examined whether similar p23 regions are involved in pathogenesis in this citrus host and in the non-natural host $N$. benthamiana. This question is important because effects observed in natural hosts (especially in woody species) and in model plants, such as $N$. benthamiana and Arabidopsis thaliana, may not be necessarily identical. To this end, the p23 gene from CTV T36 and three truncated versions thereof under the control of the CaMV 35S promoter were used to transform Mexican lime. Examination by Southern, Northern, and Western blot analyses identified several transgenic lines for each construct expressing p23 and its deletion mutants (Fig. 8; Supplementary Fig. S3). Although expression of a fragment comprising only the N-terminal 99 amino acids (p23 100 -209) did not incite morphological aberrations in transgenic plants, expression of the fragment comprising the N-terminal 157 amino acids (p23 158-209) elicited CTV-like leaf symptoms and stem pitting similar to, albeit milder than, those resulting from expressing the complete p23 protein (Fig. 8). Moreover, deletion of the fragment delimited by amino acids 50 and 86 (p23 $\Delta 50-86)$ disabled induction of developmental aberrations (data not shown), thus demarcating the region responsible for pathogenesis of p23 in citrus to a 157-amino-acid fragment that includes the $\mathrm{Zn}$ finger domain and flanking basic motifs. Altogether, these data support the idea that similar regions of p23 may determine pathogenesis in Mexican lime and $N$. benthamiana, and that results obtained with this experimentally more tractable herbaceous plant may serve, at least in part, to anticipate results with transgenic citrus plants, the generation of which demand much more effort and time.

\section{DISCUSSION}

Discerning the subcellular localization of a protein is crucial for understanding its biological role. Within the genus Closterovirus, CTV is unique in encoding a protein, p23, with different functions - in replication or accumulation, pathogenesis, suppression of RNA silencing, and, possibly, movement-which may be partially interdependent. From a structural perspective, p23 contains a putative Zn-finger domain flanked by motifs rich in basic amino acids required for RNA binding in vitro and for asymmetrical accumulation of plus and minus strands during RNA replication (López et al. 2000; Satyanarayana et al. 2002). The three cysteines and the histidine presumably coordinating the $\mathrm{Zn}$ ion are strictly conserved in essentially all CTV isolates deposited in databases, as also are most of the flanking basic amino acids between positions 50 and 86, and some additional motifs rich in basic amino acids (Sambade et al. 2003). Here, we report on another remarkable feature of p23: although there are examples of nucleolar proteins encoded by some DNA and RNA plant viruses (Taliansky et al. 2010), p23 is the first closterovirus protein with preferential localization in the nucleolus and Cajal bodies independently of other viral factors. This peculiar subcellular localization of p23 most likely determines some of its functions, while others may be related to p23 accumulating additionally in plasmodesmata (discussed below).

Our deletion and substitution analyses indicate that the NoLS of p23 is bipartite and includes regions or motifs delimited by positions 50 to 86 and 143 to 155 , both rich in basic amino acids and the first also encompassing a Zn-finger domain. At least three other proteins encoded by ssRNA (+) viruses have, like p23, bipartite NoLS with characteristic basic amino acid stretches: the umbravirus Groundnut rosette virus (GRV) ORF3 protein (Kim et al. 2007; Ryabov et al. 2004), the potyvirus Potato virus A (PVA) NIa (VPg) (Carrington et al. 1991; Schaad et al. 1996; Rajamäki and Valkonen 2009), and the cucumovirus Cucumber mosaic virus (CMV) 2b (Duan et al. 2012; González et al. 2010). In GRV ORF3 protein, mutations that block its nucleolar localization (or nuclear export) concurrently hamper assembly of cytoplasmic viral ribonucleoprotein particles and their long-distance movement, a process in which the nucleolar protein fibrillarin is also involved (Canetta et al. 2008; Kim et al. 2007). PVA VPg protein, which has an RSS activity dependent on its localization to the nucleolus and Cajal bodies, also interacts with fibrillarin but, although depletion of the latter reduces accumulation of PVA, it does not affect its long-distance movement (Rajamäki and Valkonen 2009), suggesting a different role for fibrillarin in GVR and PVA (Taliansky et al. 2010). On the other hand, whereas the interactions detected in planta between the CMV RSS $2 \mathrm{~b}$ and AGO1, AGO4, and AGO6 also require nucleolar targeting of $2 b$ (Duan et al. 20012; González et al. 2010; Hamera et al. 2012; Zhang et al. 2006), the interactions between the CMV $2 \mathrm{~b}$ protein with fibrillarin have not been examined. However, in contrast to p23, neither GRV ORF3, PVA VPg, nor CMV 2b have a predicted Zn-finger forming part of the NoLS. It is unlikely that the nucleolar localization of p23 may be directly related to its involvement in the replication of CTV, because this process occurs in the cytoplasm. In contrast, our finding that p23 additionally targets plasmodesmata is consistent with this protein facilitating CTV cell-to-cell (and indirectly systemic) movement, in agreement with data that support a role for p23 in enhancing systemic infection and virus accumulation as well as in escaping from the phloem in some natural hosts (Fagoaga et al. 2011). Whether these functions are mediated by interactions of p23 with fibrillarin or with one or more members of the AGO family (which, incidentally, might account for the RSS activity of p23) remains to be determined.

Most regions of p23 appear involved in its RSS activity because the seven deletion mutants and 9 of the 10 substitution mutants examined lost their RSS activity, concordant with observations showing that the RSS activity of other proteins from distinct RNA viruses is also very sensitive to sequence changes, including single amino acid substitutions (Martínez-Touriño and Hernández 2009; Qiu et al. 2002). Because vsRNAs accumulate to high levels in CTV-infected citrus species (Fagoaga et al. 2006; Ruiz-Ruiz et al. 2011), it is unlikely that p23 may act by binding dsRNA precursors and blocking their subsequent DCLmediated processing; alternatively, vsRNA sequestration or inactivation of one or more AGO appear to be more feasible mechanisms, especially considering that accumulation in Mexican lime of siRNAs derived from a CTV transgene is not sufficient for conferring protection against the virus (López et al. 2010; Soler et al. 2012). Additionally, p23 might facilitate host epigenetic modifications through the transport of short interfering RNA to the nucleus, as has been recently proposed for the CMV 2b protein (Kanazawa et al. 2011). Nucleolar localization of p23 appears related to suppression of RNA silencing because i) the only mutant $(\mathrm{p} 23 \mathrm{H} 75)$ of the 17 tested that retained the RSS activity was targeted to the nucleolus and ii) none of the mutants that lost the nucleolar localization (14 of 17) kept the RSS activity. Because the remaining two mutants (p23 $\Delta 106-114$ and p23 $\Delta 158-209$ ) localized to the nucleolus but did not display RSS activity, these results together indicate that RSS activity demands nucleolar localization while nucleolar localization is not sufficient for RSS activity. 
The ability of p23 to incite symptoms (when expressed in $N$. benthamiana from a PVX sgRNA or in Mexican lime from a transgene) and its RSS activity (estimated by transitory agroexpression in $N$. benthamiana) are not strictly related, as revealed by the p23 $\Delta 158-209$ mutant, which induces symptoms similar to p23 but lacks detectable RSS activity. Therefore, these results support the view that symptoms incited by viruses are not necessarily a consequence of their RSS (Díaz-Pendón and Ding 2008; Jay et al. 2011). Moreover, induction of phenotypic aberrations by p23 appears associated to its nucleolar localization, given that p23 $158-209$ and p23H75, the only two mutants inciting symptoms, are targeted to the nucleolus. However, this subnuclear localization is not sufficient by itself because mutant p23 $\Delta 106$ 114 , also targeted to the nucleolus, does not incite phenotypic aberrations. This latter result also indicates that the 106-114 motif harbors a pathogenic determinant.

On the other hand, the pathogenic determinants of p23 involved in symptoms resulting from its expression via a PVX sgRNA in $N$. benthamiana and from its transgenic expression in citrus are restricted to the N-terminal 157-amino-acid fragment that includes the $\mathrm{Zn}$-finger domain and flanking basic motifs, suggesting that p23 affects similar pathways in both hosts. However, transgenic expression of p23 is toxic to citrus, particularly to sweet and sour orange, in which high levels of the transcript but not of the protein were observed (Fagoaga et al. 2005). In contrast, transgenic expression of this protein in $N$. benthamiana does not result in a visible phenotype (Fagoaga et al. 2005), indicating that this non-natural host species is more tolerant and that symptom induction demands considerably higher levels of p23, or that p23 might induce different epigenetic modifications in both hosts.

Finally, it is interesting to note that our finding that CTVp23 has a predominant nucleolar localization, to a good extent determined by basic amino acid motifs and a Zn-finger domain, poses the question of whether other proteins encoded in the $3^{\prime}$ proximal region of the genomic RNA of distinct filamentous viruses in which these two elements are conserved might also have similar subcellular localization. In such a case, the number of viral-encoded proteins with NoLS would expand significantly, considering that these viruses include Grapevine virus A, Grapevine virus $B(\mathrm{GVB})$, and Heracleum latent virus (genus Vitivirus); Garlic common latent virus, Potato virus $S$, Potato virus $M$, and Blueberry scorch virus (genus Carlavirus) (Chiba et al. 2006); and, more recently, Beet necrotic yellow vein virus (BNYVV) (genus Benyvirus) (Chiba et al. 2013). Indeed, subsequent work has involved the Zn-finger domain and basic motifs of the small protein p12 (encoded by Chrysanthemum virus $B$ [CVB], another member of genus Carlavirus) in its predominant accumulation in the nucleus (but not specifically in the nucleolus), as well as in nucleic acid binding and induction of a hypersensitive response in N. benthamiana when expressed from PVX (Lukhovitskaya et al. 2009). Moreover, results with p14 of BNYVV and p14 of GVB show that they also accumulate preferentially in the nucleolus (Chiba et al. 2013) and the nucleus (S. W. Davino, S. RuizRuiz, and R. Flores, unpublished data), respectively. Therefore, why some proteins with basic amino acid motifs and a Zn-finger domain are targeted to the nucleolus, like CTV-p23 and BNYVV-p14, or to the nucleus, like CVB-p12 and GVBp14, remains an unanswered and challenging question.

\section{MATERIALS AND METHODS}

\section{Recombinant plasmids for expressing p23 and its truncated and point-mutated versions.}

The CTV gene coding for p23 and its fragments coding for seven deletion mutants (p23 $\Delta 50-86$, p23 $\Delta 50-66$, p23 $\Delta 67-86$, p23 $\Delta 106-114$, p23 $2100-209$, p23 $2125-209$, and p23 $\Delta 158-209)$ and 10 alanine-substituted versions (p23R51/K52, p23R59/R61/ R63, p23C68/C71/H75/C85, p23C71, p23H75, p23R73/K74, p23K77/K80/R83/K84/K86, p23R143/K145/R147, p23R150/ R151/R155, and p23R143/K145/R147/R150/R151/R155), were polymerase chain reaction (PCR) amplified with appropriate primers (Supplementary Table S1) from a complete cDNA clone of the CTV genotype T36 (Satyanarayana et al. 2001) or from cDNA clones of p23 with specific deletions (López et al. 2000). Then, the DNA coding for the GFP or RFP was fused in frame to generate by translation the recombinant $\mathrm{p} 23-\mathrm{GFP}$ or $\mathrm{p} 23-$ RFP, as well as the deleted or point-substituted versions of p23-GFP. All the constructs, flanked by the $35 \mathrm{~S}$ promoter of CaMV and the NOS-t, were inserted in the pMOG binary vector (Knoester et al. 1998) and electroporated into Agrobacterium tumefaciens strains C58 or EHA105.

\section{Confocal laser-scanning microscopy.}

The bacterial cultures, resuspended in infiltration buffer (10 $\mathrm{mM}$ MES, pH 5.6; $10 \mathrm{mM} \mathrm{MgCl}_{2}$; and $150 \mu \mathrm{M}$ acetosyringone) to a final optical density at $600 \mathrm{~nm}$ of 0.5 , were incubated for $3 \mathrm{~h}$ at room temperature, then infiltrated in leaves of $N$. benthamiana and C. macrophylla. In co-infiltration assays, equal volumes of the bacterial suspensions were mixed before infiltration. Plants were kept in growth chambers (16 h of light at $25^{\circ} \mathrm{C}$ and $8 \mathrm{~h}$ of darkness at $22^{\circ} \mathrm{C}$ ), and the agroinfiltrated leaves were examined 2 days later with a confocal laser-scanning microscope (Leica TCS-SL, Heidelberg, Germany) equipped with appropriate emission sources and filters. Markers for different cell organella used in co-localization experiments included fibrillarin fused to the RFP, which specifically marks the nucleolus and Cajal bodies, and the TMV-MPs fused to RFP and of PNRSV-MP-YFP, which specifically mark plasmodesmata.

\section{Suppression of RNA silencing assays.}

Lower leaves of the transgenic line $16 \mathrm{c}$ of $N$. benthamiana, constitutively expressing GFP (provided by D. C. Baulcombe) (Ruiz et al. 1998), were co-infiltrated with A. tumefaciens C58 cultures harboring pMOG binary plasmids for expressing GFP and p23 or its deletion and point-substitution mutants as indicated above. Following irradiation with a UV lamp (Black Ray model B-100AP, UVP, Upland, CA, U.S.A.), the fluorescence emitted by GFP in the infiltrated patches was recorded with a Nikon D-200 digital camera equipped with a yellow filter. Binary plasmids, either empty or expressing the silencing suppressor HcPro of Tobacco etch virus (Kasschau and Carrington 1998), were used as negative and positive controls, respectively.

\section{Expression of p23 from a PVX vector.}

The CTV gene $p 23$ and its seven deletion and 10 point-substitution mutants were cloned into the PVX-derived plasmid pPVX202 (Sablowski et al. 1995), using EagI and SalI restriction sites incorporated in the corresponding primers. The resulting constructs were mechanically inoculated into three leaves (15 $\mu \mathrm{g}$ of DNA per leaf) of $N$. benthamiana plants, and symptoms were observed at 7, 10, and 15 dpi and photographed. Total nucleic acid preparations were obtained at these time intervals from $100 \mathrm{mg}$ of infected leaf tissue using a standard protocol (Ancillo et al. 2007).

\section{RNA fractionation and Northern blot analysis.}

Aliquots of total nucleic acid preparations from N. benthamiana were fractionated by electrophoresis in denaturing $0.9 \%$ agarose/formaldehyde gels (for PVX gRNA and sgRNAs), in $5 \%$ agarose/formaldehyde gels (for GFP mRNA), or in $17 \%$ 
polyacrylamide/urea gels (for sRNAs), stained with ethidium bromide, and transferred to Hybond-N+ nylon membranes (Roche Diagnostics, Mannheim, Germany). Digoxigenin-labeled riboprobes specific for GFP $\mathrm{mRNA}$ and the coat protein gene of PVX were generated by in vitro transcription. After overnight hybridization at $68^{\circ} \mathrm{C}$ (for GFP mRNA and for PVX gRNA and $\mathrm{sgRNAs}$ ) or $42^{\circ} \mathrm{C}$ (for sRNAs) in the ULTRAhyb hybridization buffer (Ambion, Austin, TX, U.S.A.), the membranes were washed twice with $2 \times \mathrm{SSC}(1 \times \mathrm{SSC}$ is $0.15 \mathrm{M}$ $\mathrm{NaCl}$ plus $0.015 \mathrm{M}$ sodium citrate) plus $0.1 \%$ sodium dodecyl sulfate (SDS) for $10 \mathrm{~min}$ at room temperature, twice with $0.1 \times$ SSC plus $0.1 \%$ SDS for $15 \mathrm{~min}$ at $42^{\circ} \mathrm{C}$, and revealed with the chemiluminescent substrate disodium 3-(4-methoxyspiro \{1,2dioxetane-3,2'-(5'-chloro)tricyclo[3.3.1.1]decan \}-4-yl) phenyl phosphate (CSPD) (Roche Diagnostics) and exposure to X-ray film. Equal loading was assessed by UV spectrophotometry and by the intensity of $4 \mathrm{~S}$ RNA bands after electrophoresis in $5 \%$ polyacrylamide/urea gels.

\section{Citrus transformation and analysis.}

Recombinant plasmids pMOG-p23 $\Delta 50-86$, pMOG-p23 $\Delta 100$ 209, and pMOG-p23 $\Delta 158-209$ were digested with HindIII and the cognate expression cassettes were subcloned into the vector pBin19-sgfp, between the nos-pro/nptII/nos-ter and $35 \mathrm{~S}-\mathrm{pro} / \mathrm{sgfp} /$ nos-ter cassettes. The empty vector and its three derivatives were electroporated into A. tumefaciens EHA105 and used to transform by co-cultivation internodal stem segments of Mexican lime. Selection and PCR analysis of transformants were as previously reported (Ghorbel et al. 2001). Buds from Mexican lime transformed with each of the deleted versions of gene $p 23$ and with the empty vector, and buds from two lines of Mexican lime transformed with the wt p23 obtained previously (Ghorbel et al. 2001), were propagated by grafting onto seedlings of Carrizo citrange $(C$. sinensis $\times$ Poncirus trifoliata) and observed weekly for 3 years. Leaf details were observed with a Leica MZ 16 stereomicroscope and photographed with a Leica DFC490 camera (Leica Microsystems).

To analyze the integrity and copy number of the transgene cassettes in Mexican lime, aliquots $(15 \mu \mathrm{g})$ of leaf DNA, extracted as described previously (Dellaporta et al. 1983), were digested with EcoRI, which cuts the T-DNA once, or with Hind III, which excises the cassette. After electrophoresis in $1 \%$ agarose gels and staining with ethidium bromide, DNA fragments were blotted onto a nylon membrane, fixed by UV irradiation, hybridized with a digoxigenin-labeled fragment of gene $p 23$ according to the manufacturer's instructions (Boehringer, Mannheim, Germany), and detected by chemiluminescence with the CSPD substrate.

To assess transcription of the transgene, total leaf nucleic acid preparations from Mexican lime were obtained with buffersaturated phenol and fractionated with $2 \mathrm{M} \mathrm{LiCl}$ (Carpenter and Simon 1998). Aliquots $(20 \mu \mathrm{g})$ of the insoluble RNAs were electrophoresed in $1 \%$ agarose gels with formaldehyde, stained with ethidium bromide, blotted onto a nylon membrane, and fixed by UV irradiation. Prehybridization, hybridization, and washing of the membranes were as reported previously (Flores 1986), except that hybridization was at $50^{\circ} \mathrm{C}$ in $50 \%$ formamide. The radioactive $p 23$-specific cDNA probe was prepared with Ready-To-Go DNA labeling beads (Amersham Pharmacia Biotech Inc., Piscataway, NJ, U.S.A.).

Finally, to determine the accumulation of p23 and its deleted mutants, total leaf protein preparations from Mexican lime were extracted with $100 \mathrm{mM}$ Tris- $\mathrm{HCl}, \mathrm{pH} 6.8$ (containing $0.3 \% \beta$-mercaptoethanol and $1 \mathrm{mM}$ phenyl-methyl-sulfonyl fluoride), and quantified with the Protein Assay Dye Reagent (Bio-Rad, Hercules, CA, U.S.A.) (Bradford 1976). Aliquots
$(50 \mu \mathrm{g})$ were electrophoresed in SDS-polyacrylamide gels $(12 \%)$, electroblotted onto polyvinylidene diflouride membranes, and probed with a polyclonal antibody $(1 \mu \mathrm{g} / \mathrm{ml})$ against p23 $\Delta 50-86$. To prepare this antibody, p23 $\Delta 50-86$ fused to the maltose binding protein was expressed in bacterial cells, purified, and injected into a rabbit as reported previously (López et al. 2000). The rabbit was bled 5 days after the last immunization and the serum was recovered by centrifugation, titrated, and kept at $-20^{\circ} \mathrm{C}$. To avoid unspecific binding, the polyclonal antiserum was purified through a HiTrap Protein G HP column (Amersham Pharmacia Biotech Inc.), and a diluted antibody solution $(15 \mu \mathrm{g} / \mathrm{ml})$ was applied to an enzyme-linked immunosorbent assay plate coated with a crude extract of Mexican lime prepared at a 1:10 ratio (tissue weight to carbonate buffer volume) and kept at $4^{\circ} \mathrm{C}$ for $16 \mathrm{~h}$. The antibody preparation was recovered and the treatment was repeated eight times. Binding of the antibody to proteins transferred to membranes was detected with an anti-rabbit immunoglobulin $\mathrm{G}$ (whole molecule) antibody from goat conjugated with alkaline phosphatase (Sigma-Aldrich, St. Louis), and visualized with 5bromo-4-chloro-3-indolyl phosphate/nitro blue tetrazolium (Sigma-Aldrich).

\section{ACKNOWLEDGMENTS}

This research was supported by a grant (Prometeo/2008/121) from the Generalitat Valenciana, Spain, and by a grant (AGL2009-08052) from the Ministerio de Ciencia e Innovación-Fondo Europeo de Desarrollo Regional. S. Ruiz-Ruiz has been additionally supported by a postdoctoral contract from the Generalitat Valenciana (APOSTD/2012/020, Program VALi+d). We thank M. Taliansky and J. Shaw for some constructions, and M. T. Gorris and M. Cambra for the p23 $\Delta 50-86$ polyclonal antiserum. R. Flores, L. Peña, P. Moreno, and L. Navarro initially conceived the work, which was enriched with the input of the remaining authors. S. Ruiz-Ruiz and N. Soler performed most of the experimental work with $N$. benthamiana and citrus, respectively. J. Sánchez-Navarro, C. Fagoaga, and C. López provided materials and ideas on how to use them. R. Flores, L. Peña, and P. Moreno wrote the initial draft of the manuscript, with suggestions from all the other authors being incorporated into the final version.

\section{LITERATURE CITED}

Albiach-Martí, M. R., Robertson, C., Gowda, S., Tatineni, S., Belliure, B. Garnsey, S. M., Folimonova, S. Y., Moreno, P., and Dawson, W. O. 2010. The pathogenicity determinant of Citrus tristeza virus causing the seedling yellows syndrome maps at the $3^{\prime}$-terminal region of the viral genome. Mol. Plant Pathol. 11:55-67.

Ambrós, S., El-Mohtar, C., Ruiz-Ruiz, S., Peña, L., Guerri, J., Dawson, W. O., and Moreno, P. 2011. Agroinoculation of Citrus tristeza virus causes systemic infection and symptoms in the presumed nonhost Nicotiana benthamiana. Mol. Plant-Microbe Interact. 24:1119-1131.

Ancillo, G., Gadea, J., Forment, J., Guerri, J., and Navarro, L. 2007. Class prediction of closely related plant varieties using gene expression profiling. J. Exp. Bot. 58:1927-1933.

Bar-Joseph, M., Marcus, R., and Lee, R. F. 1989. The continuous challenge of citrus tristeza virus control. Annu. Rev. Phytopathol. 27:291316 .

Barneche, F., Steinmetz, F., and Echeverria, M. 2000. Fibrillarin genes encode both a conserved nucleolar protein and a novel small nucleolar RNA involved in ribosomal RNA methylation in Arabidopsis thaliana. J. Biol. Chem. 275:27212-27220.

Bradford, M. M. 1976. A rapid and sensitive method for the quantitation of microgram quantities of protein utilizing the principle of protein-dye binding. Anal. Biochem. 72:248-254.

Brigneti, G., Voinnet, O., Li, W. X., Ji, L. H., Ding, S. W., and Baulcombe, D. C. 1998. Viral pathogenicity determinants are suppressors of transgene silencing in Nicotiana benthamiana. EMBO (Eur. Mol. Biol. Organ.) J. 17:6739-6746.

Canetta, E., Kim, S. H., Kalinina, N. O., Shaw, J., Adya, A. K., Gillespie, T., Brown, J. W. S., and Taliansky, M. 2008. A plant virus movement protein forms ringlike complexes with the major nucleolar protein, fibrillarin, in vitro. J. Mol. Biol. 376:932-937.

Carpenter, C. D., and Simon, A. E. 1998. Preparation of RNA. Methods Mol. Biol. 82:85-89. 
Carrington, J. C., Freed, D. D., and Leinicke, A. J. 1991. Bipartite signal sequence mediates nuclear translocation of the plant potyviral NIa protein. Plant Cell 3:953-962.

Chiba, M., Reed, J. C., Prokhnevsky, A. I., Chapman, E. J., Mawassi, M., Koonin, E. V., Carrington, J. C., and Dolja, V. V. 2006. Diverse suppressors of RNA silencing enhance agroinfection by a viral replicon. Virology 346:7-14.

Chiba, S., Hleibieh, K., Delbianco, A., Klein, E., Ratti, C., Ziegler-Graff, V., Bouzoubaa, S. E., and Gilmer, D. 2013. The benyvirus RNA silencing suppressor is essential for long-distance movement, requires both Zn-finger and NoLS basic residues but not a nucleolar localization for its silencing suppression activity. Mol. Plant-Microbe Interact. 26:168181.

Csorba, T., Pantaleo, V., and Burgyán, J. 2009. RNA silencing: An antiviral mechanism. Adv. Virus Res. 75:35-71.

Dalmay, T., Hamilton, A., Rudd, S., Angell, S., and Baulcombe, D. C. 2000. An RNA-dependent RNA polymerase gene in Arabidopsis is required for posttranscriptional gene silencing mediated by a transgene but not by a virus. Cell 101:543-553.

Dellaporta, S., Wood, J., and Hicks, J. 1983. A plant DNA minipreparation: Version II. Plant Mol. Biol. Rep. 1:19-21.

Díaz-Pendón, J. A., and Ding, S. W. 2008. Direct and indirect roles of vira suppressors of RNA silencing in pathogenesis. Annu. Rev. Phytopathol. 46:303-326

Ding, S. W. 2010. RNA-based antiviral immunity. Nat. Rev. Immunol. 10:632-644.

Dolja, V. V., Kreuze, J. F., and Valkonen, J. P. 2006. Comparative and functional genomics of closteroviruses. Virus Res. 117:38-51.

Duan, C. G., Fang, Y. Y., Zhou, B. J., Zhao, J. H., Hou, W. N., Zhu, H., Ding, S. W., and Guo, H. S. 2012. Suppression of Arabidopsis ARGONAUTE1-mediated slicing, transgene-induced RNA silencing, and DNA methylation by distinct domains of the Cucumber mosaic virus $2 \mathrm{~b}$ protein. Plant Cell 24:259-274.

Fagoaga, C., López, C., Moreno, P., Navarro, L., Flores, R., and Peña, L. 2005. Viral-like symptoms induced by the ectopic expression of the p23 of Citrus tristeza virus are citrus specific and do not correlate with the pathogenicity of the virus strain. Mol. Plant-Microbe Interact. 18:435445 .

Fagoaga, C., López, C., Hermoso de Mendoza, A. H., Moreno, P., Navarro, L., Flores, R., and Peña, L. 2006. Post-transcriptional gene silencing of the p23 silencing suppressor of Citrus tristeza virus confers resistance to the virus in transgenic Mexican lime. Plant Mol. Biol. 66:153-165.

Fagoaga, C., Pensabene, G., Moreno, P., Navarro, L., Flores, R., and Peña L. 2011. Ectopic expression of the p23 silencing suppressor of Citrus tristeza virus differentially modifies viral accumulation and tropism in two transgenic woody hosts. Mol. Plant Pathol. 12:898-910.

Flores, R. 1986. Detection of citrus exocortis viroid in crude extracts by dot-blot hybridization: Conditions for reducing spurious hybridization results and for enhancing the sensitivity of the technique. J. Virol. Methods 13:161-169.

Folimonova, S. Y., Folimonov, A. S., Tatineni, S., and Dawson, W. O. 2008. Citrus tristeza virus: Survival at the edge of the movement continuum. J. Virol. 82:6546-6556.

Ghorbel, R., López, C., Fagoaga, C., Moreno, P., Navarro, L., Flores, R., and Peña, L. 2001. Transgenic citrus plants expressing the Citrus tristeza virus p23 protein exhibit viral-like symptoms. Mol. Plant Pathol. 2:27-36.

González, I., Martínez, L., Rakitina, D. V., Lewsey, M. G., Atencio, F. A., Llave, C., Kalinina, N. O., Carr, J. P., Palukaitis, P., and Canto, T. 2010. Cucumber mosaic virus $2 \mathrm{~b}$ protein subcellular targets and interactions: Their significance to RNA silencing suppressor activity. Mol. PlantMicrobe Interact. 23:294-303.

Hamera, S., Song, X., Su, L., Chen, X., and Fang, R. 2012. Cucumber mosaic virus suppressor $2 \mathrm{~b}$ binds to AGO4-related small RNAs and impairs AGO4 activities. Plant J. 69:104-115.

Hamilton, A. J., and Baulcombe, D. C. 1999. A species of small antisense RNA in posttranscriptional gene silencing in plants. Science 286:950952.

Herranz, M. C., Sánchez-Navarro, J. A., Saurí, A., Mingarro, I., and Pallás, V. 2005. Mutational analysis of the RNA-binding domain of the Prunus necrotic ringspot virus (PNRSV) movement protein reveals its requirement for cell-to-cell movement. Virology 339:31-41.

Hilf, M. E., Karasev, A. V., Pappu, H. R., Gumpf, D. J., Niblett, C. L., and Garnsey, S. M. 1995. Characterization of citrus tristeza virus subgenomic RNAs in infected tissue. Virology 208:576-582.

Hiscox, J. A. 2007. RNA viruses: Hijacking the dynamic nucleolus. Nat Rev. Microbiol. 5:119-127.

Jacobson, S. E., Running, M. P., and Meyerowitz, E. M. 1999. Disruption of an RNA helicase/RNAse III gene in Arabidopsis causes unregulated cell division in floral meristems. Development 126:5231-5243.

Jay, F., Wang, Y., Yu, A., Taconnat, L., Pelletier, S., Colot, V., Renou, J. P., and Voinnet, O. 2011. Misregulation of AUXIN RESPONSE FACTOR 8 underlies the developmental abnormalities caused by three distinct viral silencing suppressors in Arabidopsis. PLoS Pathog. 7:e1002035.

Kanazawa, A., Inaba, J., Shimura, H., Otagaki, S., Tsukahara, S., Matsuzawa, A., Kim, B. M., Goto, K., and Masuta, C. 2011. Virusmediated efficient induction of epigenetic modifications of endogenous genes with phenotypic changes in plants. Plant J. 65:156-168.

Karasev, A. V., Boyko, V. P., Gowda, S., Nikolaeva, O. V., Hilf, M. E., Koonin, E. V., Niblett, C. L., Cline, K., Gumpf, D. J., Lee, R. F., Garnsey, S. M., Lewandowski, D. J., and Dawson, W. O. 1995. Complete sequence of the Citrus tristeza virus RNA genome. Virology 208:511-520

Kasschau, K. D., and Carrington, J. C. 1998. A counterdefensive strategy of plant viruses: Suppression of posttranscriptional gene silencing. Cell 95:461-470.

Kim, S. H., Ryabov, E. V., Kalinina, N. O., Rakitina, D. V., Gillespie, T. MacFarlane, S., Haupt, S., Brown, J. W. S., and Taliansky, M. 2007. Cajal bodies and the nucleolus are required for a plant virus systemic infection. EMBO (Eur. Mol. Biol. Organ.) J. 26:2169-2179.

Knoester, M., van Loon, L. C., van den Heuvel, J., Hennig, J., Bol, J. F., and Linthorst, H. J. M. 1998. Ethylene-insensitive tobacco lacks nonhost resistance against soil-borne fungi. Proc. Natl. Acad. Sci. U.S.A. 95:1933-1937.

Kosugi, S., Hasebe, M., Matsumura, N., Takashima, H., Miyamoto-Sato, E., Tomita, M., and Yanagawa, H. 2009. Six classes of nuclear localization signals specific to different binding grooves of importin alpha. J. Biol. Chem. 284:478-485.

López, C., Navas-Castillo, J., Gowda, S., Moreno, P., and Flores, R. 2000. The $23 \mathrm{kDa}$ protein coded by the 3 '-terminal gene of Citrus tristeza virus is an RNA-binding protein. Virology 269:462-470.

López, C., Cervera, M., Fagoaga, C., Moreno, P., Navarro, L., Flores, R. and Peña, L. 2010. Accumulation of transgene-derived siRNAs is not sufficient for RNAi-mediated protection against Citrus tristeza virus (CTV) in transgenic Mexican lime. Mol. Plant Pathol. 11:33-41.

Lu, R., Folimonov, A., Shintaku, M., Li, W. X., Falk, B. W., Dawson, W. O., and Ding. S. W. 2004. Three distinct suppressors of RNA silencing encoded by a $20-\mathrm{kb}$ viral RNA genome. Proc. Natl. Acad. Sci. U.S.A. 101:15742-15747.

Lukhovitskaya, N. I., Ignatovich, I. V., Savenkov, E. I., Schiemann, J., Morozov, S. Y., and Solovyev, A. G. 2009. Role of the zinc-finger and basic motifs of Chrysanthemum virus $B$ p12 protein in nucleic acid binding, protein localization and induction of a hypersensitive response upon expression from a viral vector. J. Gen. Virol. 90:723-733.

Martínez-Touriño, S., and Hernández, C. 2009. Inhibition of RNA silencing by the coat protein of Pelargonium flower break virus: Distinctions from closely related suppressors. J. Gen. Virol. 90:519-525.

Mawassi, M., Mietkiewska, E., Gofman, R., Yang, G., and Bar-Joseph, M. 1996. Unusual sequence relationships between two isolates of Citrus tristeza virus. J. Gen. Virol. 77:2359-2364.

Molnar, A., Csorba, T., Lakatos, L., Varallyay, E., Lacomme, C., and Burgyán, J. 2005. Plant virus-derived small interfering RNAs originate predominantly from highly structured single-stranded viral RNAs. J. Virol. 79:7812-7818.

Moreno, P., Ambrós, S., Albiach-Martí, M. R., Guerri, J., and Peña, L. 2008. Citrus tristeza virus: A pathogen that changed the course of the citrus industry. Mol. Plant Pathol. 9:251-268.

Omarov, R. T., Cioperlik, J. J., and Sholthof, H. B. 2007. RNAi-associated ssRNA-specific ribonucleases in tombusvirus P19 mutant-infected plants and evidence for a discrete siRNA-containing effector complex. Proc. Natl. Acad. Sci. U.S.A. 104:1714-1719.

Pantaleo, V., Szittya, G., and Burgyán, J. 2007. Molecular bases of viral RNA targeting by viral small interfering RNA-programmed RISC. J. Virol. 81:3797-3806.

Pruss, G., Ge, X., Shi, X. M., Carrington, J. C., and Vance, V. B. 1997. Plant vira1 synergism: The potyviral genome encodes a broad-range pathogenicity enhancer that transactivates replication of heterologous viruses. Plant Cell 9:859-868.

Qi, Y., Denli, A. M., and Hannon, G. J. 2005. Biochemical specialization within Arabidopsis RNA silencing pathways. Mol. Cell 19:421-428.

Qiu, W. P., Park, J. W., and Scholthof, H. B. 2002. Tombusvirus P19-mediated suppression of virus induced gene silencing is controlled by genetic and dosage features that influence pathogenicity. Mol. PlantMicrobe Interact. 15:269-280.

Rajamäki, M. L., and Valkonen, J. P. T. 2009. Control of nuclear and nucleolar localization of nuclear inclusion protein a of picorna-like Potato virus A in Nicotiana species. Plant Cell 21:2485-2502.

Ruiz, M. T., Voinnet, O., and Baulcombe, D. C. 1998. Initiation and maintenance of virus-induced gene silencing. Plant Cell 10:937-946. 
Ruiz-Ruiz, S., Navarro, B., Gisel, A., Peña, L., Navarro, L., Moreno, P., Di Serio, F., and Flores, R. 2011. Citrus tristeza virus infection induces the accumulation of viral small RNAs (21-24-nt) mapping preferentially at the 3'-terminal region of the genomic RNA and affects the host small RNA profile. Plant Mol. Biol. 75:607-619.

Ryabov, E. V., Kim, S. H., and Taliansky, M. 2004. Identification of a nuclear localization signal and nuclear export signal of the umbraviral long-distance RNA movement protein. J. Gen. Virol. 85:1329-1333.

Sablowski, R. W. M., Baulcombe, D. C., and Bevan, M. 1995. Expression of a flower-specific Myb protein in leaf cells using a viral vector causes ectopic activation of a target promoter. Proc. Natl. Acad. Sci. U.S.A. 92:6901-6905.

Sambade, A., López, C., Rubio, L., Flores, R., Guerri, J., and Moreno, P. 2003. Polymorphism of a specific region in gene p23 of Citrus tristeza virus allows discrimination between mild and severe isolates. Arch. Virol. 148:2325-2340.

Satyanarayana, T., Bar-Joseph, M., Mawassi, M., Albiach-Martí, M. R., Ayllón, M. A., Gowda, S., Hilf, M. E., Moreno, P., Garnsey, S. M., and Dawson. W. O. 2001. Amplification of Citrus tristeza virus from a cDNA clone and infection of citrus trees. Virology 280:87-96.

Satyanarayana, T., Gowda, S., Ayllón, M. A., Albiach-Martí, M. R., Rabindram, R., and Dawson, W. O. 2002. The p23 protein of Citrus tristeza virus controls asymmetrical RNA accumulation. J. Virol. 76:473483.

Schaad, M. C., Haldeman-Cahill, R., Cronin, S., and Carrington, J. C. 1996. Analysis of the VPg-proteinase (NIa) encoded by Tobacco etch potyvirus: Effects of mutations on subcellular transport, proteolytic processing and genome amplification. J. Virol. 70:7039-7048.

Soler, N., Plomer, M., Fagoaga, C., Moreno, P., Navarro, L., Flores, R., and Peña, L. 2012. Transformation of Mexican lime with an intron-hairpin construct expressing untranslatable versions of the genes coding for the three silencing suppressors of Citrus tristeza virus confers complete resistance to the virus. Plant Biotechnol. J. 10:597-608.

Taliansky, M. E., Brown, J. W. S., Rajamäki, M. L., Valkonen, J. P. T., and Kalinina, N. O. 2010. Involvement of the plant nucleolus in virus and viroid infections: Parallels with animal pathosystems. Adv. Virus Res. 77:119-158.

Tomenius, K., Clapham, D., and Meshi, T. 1987. Localization by immunogold cytochemistry of the virus-coded $30 \mathrm{~K}$ protein in plasmodesmata of leaves infected with tobacco mosaic virus. Virology 160:363-371.

Vaucheret, H. 2008. Plant ARGONAUTES. Trends Plant Sci. 13:350-358.

Vives, M. C., Rubio, L., López, C., Navas-Castillo, J., Albiach-Martí, M. R., Dawson, W. O., Guerri, J., Flores, R., and Moreno, P. 1999. The complete genome sequence of the major component of a mild Citrus tristeza virus isolate. J. Gen. Virol. 80:811-816.

Voinnet, O. 2008. Use, tolerance and avoidance of amplified RNA silencing by plants. Trends Plant Sci. 13:317-328.

Voinnet, O., Pinto, Y. M., and Baulcombe, D. C. 1999. Suppression of gene silencing: A general strategy used by diverse DNA and RNA viruses of plants. Proc. Natl. Acad. Sci. U.S.A. 96:14147-14152.

Yang, Z. N., Mathews, D. H., Dodds, J. A., and Mirkov, T. E. 1999. Molecular characterization of an isolate of Citrus tristeza virus that causes severe symptoms in sweet orange. Virus Genes 19:131-142.

Zhang, X., Yuan, Y. R., Pei, Y., Lin, S. S., Tuschl, T., Patel, D. J., and Chua, N. H. 2006. Cucumber mosaic virus-encoded 2b suppressor inhibits Arabidopsis Argonaute1 cleavage activity to counter plant defense. Genes Dev. 20:3255-3268. 